Article

\title{
A Novel Hybrid Fuzzy Grey TOPSIS Method: Supplier Evaluation of a Collaborative Manufacturing Enterprise
}

\author{
Yixiong Feng ${ }^{1}\left(\mathbb{D}\right.$, Zhifeng Zhang ${ }^{1}$, Guangdong Tian ${ }^{2,3, *}$, Amir Mohammad Fathollahi-Fard ${ }^{4}$, \\ Nannan Hao ${ }^{5}$, Zhiwu Li ${ }^{6}$, Wenjie Wang ${ }^{2,3}$ and Jianrong Tan ${ }^{1}$ \\ 1 State Key Laboratory of Fluid Power and Mechatronic Systems, Zhejiang University, \\ Hangzhou 310027, China \\ 2 School of Mechanical Engineering, Shandong University, Jinan 250061, China \\ 3 Key Laboratory of High Efficiency and Clean Mechanical Manufacture (Ministry of Education), \\ Shandong University, Jinan 250061, China \\ 4 Department of Industrial Engineering and Management Systems, Amirkabir University of Technology, \\ Hafez Ave. 424, Tehran 15875-4413, Iran \\ 5 Department of Industrial Engineering, Tsinghua University, Beijing 100084, China \\ 6 Institute of Systems Engineering, Macau University of Science and Technology, Macau 999078, China \\ * Correspondence: tiangd2013@163.com; Tel.: +86-151-0431-7455
}

Received: 11 July 2019; Accepted: 22 August 2019; Published: 9 September 2019

\begin{abstract}
Recently, there is of significant interest in developing multi-criteria decision making (MCDM) techniques with large applications for real-life problems. Making a reasonable and accurate decision on MCDM problems can help develop enterprises better. The existing MCDM methods, such as the grey comprehensive evaluation (GCE) method and the technique for order preference by similarity to an ideal solution (TOPSIS), have their one-sidedness and shortcomings. They neither consider the difference of shape and the distance of the evaluation sequence of alternatives simultaneously nor deal with the interaction that universally exists among criteria. Furthermore, some enterprises cannot consult the best professional expert, which leads to inappropriate decisions. These reasons motivate us to contribute a novel hybrid MCDM technique called the grey fuzzy TOPSIS (FGT). It applies fuzzy measures and fuzzy integral to express and integrate the interaction among criteria, respectively. Fuzzy numbers are employed to help the experts to make more reasonable and accurate evaluations. The GCE method and the TOPSIS are combined to improve their one-sidedness. A case study of supplier evaluation of a collaborative manufacturing enterprise verifies the effectiveness of the hybrid method. The evaluation result of different methods shows that the proposed approach overcomes the shortcomings of GCE and TOPSIS. The proposed hybrid decision-making model provides a more accurate and reliable method for evaluating the fuzzy system MCDM problems with interaction criteria.
\end{abstract}

Keywords: grey correlation; topsis; multi-criteria decision making

\section{Introduction}

Multi-criteria decision making (MCDM) problems are utterly fatal and can be frequently observed academically in many domains, such as in manufacturing [1,2], finance [3], logistics [4], and the supply chain [5]. The rationality and correctness of the decision are quite crucial for a company. The development of an effective and efficient MCDM method to solve the optimization problems correctly is significant. 
Conventionally, frequently-used MCDM methods include the goal programming method [6], the multi-attribute value theory [7], the multi-attribute utility method [8], the delaminating sequence method [9], the analytic hierarchy process (AHP) [10], the data envelopment analysis [11], the technique for order preference by similarity to ideal solution (TOPSIS) [12,13], grey comprehensive evaluation (GCE) method [14], fuzzy comprehensive evaluation [15], artificial neural networks [16] and some other fuzzy grey based hybrid MCDM approaches [17-26] Great progress has been made and compared with the earlier methods. However, there are still some shortcomings when dealing with the problems in real-life systems. It is universally acknowledged that the criteria are interactive [27-29] and for some qualitative criteria, we can only find the fuzzy evaluation rather than numerical values [30]. However, the hypothesis that the criteria are independent is diffusely used in these methods, and the evaluation values are aggregated through linear means, which usually leads to inadequate decisions.

The fuzzy integral is considered as an effective method to improve the limit since it can take into consideration the interactions among criteria expressed by fuzzy measures when aggregating the evaluation data [31-34]. The fuzzy integral is proposed by Sugeno [35] and further developed by many researchers. The fuzzy integral mainly includes the Sugeno fuzzy integral [36], the Choquet fuzzy integral [37], the $(\mathrm{Y})$ fuzzy integral, the $(\mathrm{N})$ fuzzy integral, the $(\mathrm{H})$ fuzzy integral, the uncertain $(\mathrm{H})$ fuzzy integral, the (T) fuzzy integral, the pseudo-additive and the Pan-integrals fuzzy integral [38]. Among these fuzzy integrals, the Choquet integral is the best for dealing with the nonlinear aggregation of MCDM problems since it can well express the interactions among criteria [39,40]. The fuzzy measures mainly include the nonadditive-measures, the quasi-additive-measures, the $k$-addictive fuzzy-measures, and the $\lambda$-fuzzy-measures $[38,39]$. Although the $\lambda$-fuzzy-measures can fully represent the interactions among criteria and are easy to calculate, they can only express one kind of interaction in one group of criteria. The $k$-addictive fuzzy-measure provides us a choice between the good expression ability and the simple computation, but we cannot obtain both simultaneously.

Among the conventional MCDM methods, the TOPSIS evaluates objects according to their difference in the comprehensive closeness degree. This evaluation is determined by the distance between the positive and negative ideal solution schemes [40]. It does not take into consideration the difference of shape of the scheme. The TOPSIS method fails under two conditions. In Figure 1, points A and $\mathrm{B}$ are positive and negative ideal solution schemes; Points $\mathrm{C}, \mathrm{D}, \mathrm{E}$, and $\mathrm{F}$ are objects to evaluate. Generally, if the line $A B$ is vertically divided by line $C D$, the distance between all the points on the straight line $\mathrm{CD}$ and point $\mathrm{A}$ are equal to that between these points and point $\mathrm{B}$. The comprehensive close degrees of them are all 0.5 . If line $E F$ is vertically divided by line $A B$, the distance of points $E$ and $A$ is equal to that of points $F$ and $A$. Furthermore, the distance of points $E$ and $B$ is equal to that of points $\mathrm{F}$ and $\mathrm{B}$. The comprehensive close degrees of $\mathrm{E}$ and $\mathrm{F}$ are equal.

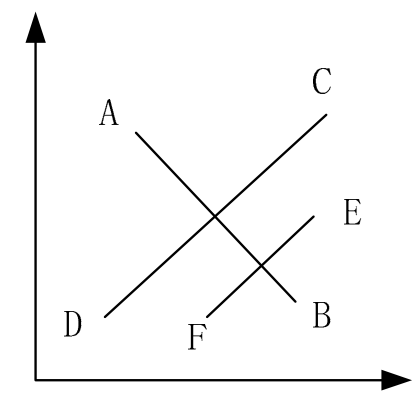

Figure 1. Technique for order preference by similarity to an ideal solution (TOPSIS) failed conditions.

The GCE method depends on the grey correlation degree, which can reflect the closeness degree between the evaluation sequences of objects [41]. It does not take into account the number and distribution of samples and is easy to implement. However, most studies focus on the construction of the grey correlation coefficients. If the shapes of evaluation sequences of some objects are very similar, the GCE method may not be able to evaluate them properly. For example, assume that the evaluation 
sequences $U_{1}, U_{2}$, and $U_{3}$ are shown in Figure 2. The correlation degree between $U_{2}$ and $U_{1}$ is the same as that between $\mathrm{U}_{3}$ and $\mathrm{U}_{1}$.

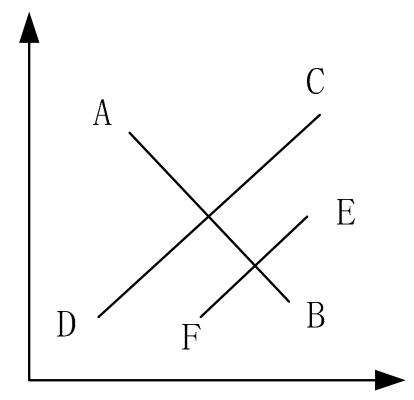

Figure 2. Grey comprehensive evaluation (GCE) failed conditions.

Other similar traditional methods, such as TOPSIS and GCE, assume that criteria are independent of each other. In this regard, to a great extent, it leads to limiting them when addressing some practical problems with interactive criteria. By considering these features of the TOPSIS and GCE approaches, this study develops a novel hybrid MCDM method called the fuzzy grey TOPSIS (FGT). By comparing the exiting methods, this research makes the following contributions.

First, the proposed method combines the GCE and TOPSIS, which improves the one-sidedness of the GCE and TOPSIS methods. Decision-makers can make a decision according to their preference through adjusting a parameter that reflects the weights of the shape and the distance factors.

Second, fuzzy measures and fuzzy integral are employed to express and integrate the interaction between the criteria that cannot be properly expressed through the existing methods.

Third, fuzzy numbers are used to help the experts make a more reasonable and accurate evaluation of some qualitative criteria.

The remainder of this paper is organized as follows: Section 2 is a literature review. Section 3 introduces the preliminaries. Section 4 presents the novel hybrid MCDM method that combines the fuzzy integral, the grey correlation, and TOPSIS. Section 5 utilizes an example of supplier evaluation of a collaborative manufacturing enterprise to illustrate the procedure, the feasibility, and effectiveness of the proposed method. Finally, conclusions are reached in Section 6.

\section{Literature Review}

Academically, many studies have been conducted on MCDM problems, and substantial progress has been made in this field. For example, Bouzarour-Amokrane et al. formulated a consensus bipolar method to solve the collaborative group MCDM problems considering the impact of human behavior, e.g., individualism, fear, caution [42]. The analysis results of the application example about real size wind farm implantation problem showed that this proposed method can be a useful decision-making tool to solve this problem [42]. Tchangani et al. proposed a bipolar aggregation method that combines weighted cardinal fuzzy measures, which can effectively overcome difficulties that dissuade the use of Choquet integral in practices to solve the fuzzy nominal classification in the MCDM problem [43]. Zhang et al. formulated a hybrid optimization approach combining the best worst method, grey relational analysis, and visekriterijumsko kompromisno rangiranje (VIKOR) to solve the MCDM problem in rail transit [44]. A multi-cell thin-walled aluminum energy-absorbing structure was applied to verify that this integrated method is valid and practical [44]. The results proved that this method provides an accurate and effective tool for the structural decision-making problem in rail transit [44]. Mousavi-Nasab and Sotoudeh-Anvari presented a new multi-criteria decision-making approach for the sustainable material selection problem [45]. Ten examples were applied to verify this proposed method [45].

TOPSIS and GCE are two of the several important methods in dealing with MCDM problems. Many researchers have a contribution to hybridization of MCDM techniques with some other method 
to make the best use of their advantages and bypass their disadvantages, as shown in Tables 1 and 2 . In addition, the fuzzy integral and fuzzy set are used to address the interaction among criteria which have been applied to many domains, as exposed in Table 3.

Table 1. Review of the technique for order preference by similarity to an ideal solution (TOPSIS).

\begin{tabular}{|c|c|c|c|}
\hline Typical Reference & Tool Type & Advantage & Limitation \\
\hline Hassan et al. [46] & TOPSIS & Flexible framework & $\begin{array}{l}\text { Experts have too } \\
\text { many rights }\end{array}$ \\
\hline Kazançoğlu et al. [47] & Fuzzy TOPSIS & Simple & $\begin{array}{l}\text { Hard to describe } \\
\text { complex systems }\end{array}$ \\
\hline Bagočius et al. [48] & TOPSIS and COPRAS, SAW & Various comparison & $\begin{array}{l}\text { Hard to describe } \\
\text { complex systems }\end{array}$ \\
\hline Yayla et al. [49] & Fuzzy TOPSIS and Fuzzy-AHP & More realistic and reliable & $\begin{array}{l}\text { Complicated and } \\
\text { abstract models }\end{array}$ \\
\hline John et al. [50] & Fuzzy TOPSIS and Fuzzy-AHP & More realistic and reliable & $\begin{array}{l}\text { Complicated and } \\
\text { abstract models }\end{array}$ \\
\hline Shanian and Savadogo [51] & Ordinary and Block TOPSIS & Simple and fast & Complicated \\
\hline Olson [52] & TOPSIS & Simple and fast & Not accurate enough \\
\hline Deng et al. [53] & $\begin{array}{l}\text { Weighted Euclidean distances } \\
\text { TOPSIS }\end{array}$ & Simple and direct & Not accurate enough \\
\hline Buyukozkan and Cifci $[54,55]$ & Fuzzy AHP and fuzzy TOPSIS & $\begin{array}{l}\text { Solving the uncertainty } \\
\text { problem of score evaluation }\end{array}$ & $\begin{array}{l}\text { Hard to describe } \\
\text { complex systems }\end{array}$ \\
\hline Zavadskas et al. [56-58] & TOPSIS, COPRAS, and ARAS & $\begin{array}{l}\text { Aggregate both quantitative } \\
\text { and qualitative criteria }\end{array}$ & $\begin{array}{l}\text { Complicated and } \\
\text { abstract models }\end{array}$ \\
\hline Yazdani and Payam [59] & Ashby, VIKOR, and TOPSIS & Various comparison & $\begin{array}{l}\text { Complicated and } \\
\text { abstract models }\end{array}$ \\
\hline
\end{tabular}

Table 2. Literature review of grey evaluation methods.

\begin{tabular}{|c|c|c|c|}
\hline Typical Reference & Tool Type & Advantage & Limitation \\
\hline $\begin{array}{c}\text { Pohekar and } \\
\text { Ramachandran [62] }\end{array}$ & $\begin{array}{l}\text { MCDM, PROMETHEE, and } \\
\text { ELECTRE }\end{array}$ & Compare in a variety of ways & $\begin{array}{l}\text { Thinking not deep } \\
\text { enough }\end{array}$ \\
\hline Hashemi et al. [64] & $\begin{array}{l}\text { Improved grey relational } \\
\text { analysis }\end{array}$ & Novel and convenient & $\begin{array}{l}\text { Hard to describe } \\
\text { complex systems }\end{array}$ \\
\hline Sarucan et al. [65] & AHP and GRA & More realistic and reliable & $\begin{array}{l}\text { Complicated and } \\
\text { abstract models }\end{array}$ \\
\hline Wang et al. $[67,68]$ & Fuzzy and weighting method & More realistic and reliable & Theory still flawed \\
\hline Lee and Lin [69] & GRA & Reasonable and efficient & $\begin{array}{c}\text { The reference factor is } \\
\text { not enough }\end{array}$ \\
\hline Abhang and Hameedullah [70] & Grey relational analysis & Effectively improve accuracy & $\begin{array}{l}\text { Complicated and } \\
\text { abstract models }\end{array}$ \\
\hline
\end{tabular}


Table 3. Literature review of fuzzy integral and fuzzy set.

\begin{tabular}{|c|c|c|c|}
\hline Typical Reference & Tool Type & Advantage & Limitation \\
\hline Aydin et al. [71] & $\begin{array}{c}\text { Fuzzy-AHP, Choquet } \\
\text { integral and trapezoidal } \\
\text { fuzzy sets }\end{array}$ & Realistic and reliable & $\begin{array}{l}\text { Complicated and } \\
\text { abstract models }\end{array}$ \\
\hline Celik et al. [72] & $\begin{array}{l}\text { VIKOR and interval type-2 } \\
\text { fuzzy sets }\end{array}$ & Effectively improve accuracy & $\begin{array}{l}\text { Complicated and } \\
\text { abstract models }\end{array}$ \\
\hline Feng et al. [73] & Fuzzy integral & Convenient & Complicated \\
\hline Tian et al. [74] & Choquet fuzzy integral & Effectively improve accuracy & Complicated \\
\hline Wu et al. [75] & $\begin{array}{l}\text { Fuzzy Integral with Particle } \\
\text { Swarm Optimization }\end{array}$ & $\begin{array}{l}\text { Solving the uncertainty } \\
\text { problem }\end{array}$ & $\begin{array}{l}\text { Dependent on } \\
\text { index selection }\end{array}$ \\
\hline Zhu et al. [76] & $\begin{array}{l}\text { Fuzzy multi-attribute } \\
\text { decision making }\end{array}$ & Novel and convenient & $\begin{array}{l}\text { Dependent on } \\
\text { index selection }\end{array}$ \\
\hline Fu and Zhao [77] & $\begin{array}{l}\text { Hesitation institution } \\
\text { fuzzy number }\end{array}$ & More realistic and reliable & $\begin{array}{l}\text { Complicated and } \\
\text { abstract model }\end{array}$ \\
\hline Lin et al. [78] & $\begin{array}{c}\text { TOPSIS and aggregation } \\
\text { approach }\end{array}$ & $\begin{array}{l}\text { Efficient and robust, realistic } \\
\text { and reasonable }\end{array}$ & $\begin{array}{l}\text { Complicated and } \\
\text { abstract model }\end{array}$ \\
\hline
\end{tabular}

\section{Preliminaries}

\subsection{The $\lambda$-Fuzzy-Measure and the Choquet Integral}

In the FGT method, the weights of all subsets of a criterion set are expressed through the $\lambda$-fuzzy-measure.

Fuzzy-measures [39]: Assume that the criterion set $X$ is nonempty and $P(X)$ denotes its power set. If the set function $g: P(X) \rightarrow[0,1]$ satisfies the following three axioms, then it is called a fuzzy-measure:

(1) Boundness

$$
g(\varnothing)=0, g(X)=1
$$

(2) Monotonicity

$$
\forall A, B \in P(X) \text {, if } A \subseteq B \text {, then } g(A) \leq g(B)
$$

(3) Weak continuity:

$$
\text { If }\left\{A_{i}\right\} \subset P(X) \text { and }\left\{A_{i}\right\} \text { is monotonic, then } \lim _{i=\infty} g\left(A_{i}\right)=g\left(\lim _{i=\infty} A_{i}\right) \text {. }
$$

$\lambda$-fuzzy-measures [39]: If the fuzzy-measure $g$ satisfy the following axiom, then it is called $\lambda$-fuzzy-measures:

If $A, B \in P(X)$ and $A \cap B=\varnothing$, then $\exists \lambda \in[-1, \infty), g(A \cup B)=g(A)+g(B)+\lambda g(A) g(B)$.

Let $X=\left\{x_{1}, x_{2}, \ldots, x_{n}\right\}$ be a finite set. If the fuzzy density of $x_{i}$ is $g_{i}$, then $g_{\lambda}$ can be calculated as follows:

$$
\begin{aligned}
g_{\lambda}\left(\left\{x_{1}, x_{2}, \ldots, x_{k}\right\}\right) & =\sum_{i=1}^{k} g_{i}+\lambda \sum_{i_{1}=1}^{k-1} \sum_{i_{2}=i_{1}+1}^{k} g_{i_{1}} g_{i_{2}} \\
& +\ldots+\lambda^{k-1} g_{1} g_{2} \ldots g_{k} \\
& =\frac{1}{\lambda}\left|\prod_{i=1}^{k}\left(1+\lambda g_{i}\right)-1\right|
\end{aligned}
$$


Choquet integral [79]: Without loss of generality, assume that the evaluation values on $n$ criteria $\left\{f\left(x_{i}\right) \mid i=1,2, \ldots, n\right\}$ satisfy $f\left(x_{1}\right) \geq \ldots \geq f\left(x_{i}\right) \geq \ldots \geq f\left(x_{n}\right)$. Then, the Choquet fuzzy integral of $f(x)$ among $g(x)$ on $X$ is:

$$
\begin{aligned}
\int f d g & =f\left(x_{n}\right) g_{\lambda}\left(X_{n}\right) \\
& +\left[f\left(x_{n-1}\right)-f\left(x_{n}\right)\right] g_{\lambda}\left(X_{n-1}\right) \\
& +\ldots+\left[f\left(x_{1}\right)-f\left(x_{2}\right)\right] g_{\lambda}\left(X_{1}\right)
\end{aligned}
$$

where $g_{\lambda}\left(X_{j}\right)=g_{\lambda}\left(\left\{x_{1}, x_{2}, \ldots, x_{j}\right\}\right)$ represents the fuzzy measure of the corresponding criterion set.

\subsection{The Correlation Coefficients}

Assume that the evaluation matrix is

$$
C_{m \times n}=\left[\begin{array}{cccc}
C_{1}(1) & C_{1}(2) & \ldots & C_{1}(n) \\
C_{2}(1) & C_{2}(1) & \cdots & C_{2}(n) \\
\vdots & & \ddots & \vdots \\
C_{m}(1) & C_{m}(2) & \cdots & C_{m}(n)
\end{array}\right],
$$

where the $i$-th row represents the evaluation sequence of the $i$-th object. $\left\{C_{*}().\right\}=\left\{C_{*}(1), C_{*}(2), \ldots, C_{*}(\mathrm{n})\right\}$ is selected as the reference sequence where $C_{*}(l)$ represents the best of the $l$-th criterion. The correlation coefficient vector of the $i$-th alternative sequence related to the reference sequence is denoted as $\xi_{i *}=\left\{\xi_{i *}(1), \xi_{i *}(2), \ldots, \xi_{i *}(n)\right\}$. We then have [80]:

$$
\xi_{i *}(k)=\frac{\operatorname{minmin}_{i}\left|C_{*}(k)-C_{i}(k)\right|+\rho \operatorname{maxmax}_{i}\left|C_{*}(k)-C_{i}(k)\right|}{\left|C_{*}(k)-C_{i}(k)\right|+\rho \operatorname{maxmax}_{i}\left|C_{*}(k)-C_{i}(k)\right|}
$$

where the resolution ratio $\rho \in[0,1]$ is usually assigned as 0.5 .

The absolute correlation degree can be found by

$$
r_{i}=\sum_{j=1}^{n}\left(w_{j} \times \xi_{i *}(j)\right) .
$$

The bigger the degree value is, the better the object is.

\subsection{The Triangle Fuzzy Number}

Triangle fuzzy number [81]: The membership function of the fuzzy number $\widetilde{n}=\left(n_{1}, n_{2}, n_{3}\right)$ is defined as

$$
f(x)=\left\{\begin{array}{rr}
\frac{x-n_{1}}{n_{2}-n_{1}}, & n_{1} \leq x<n_{2} \\
\frac{x-n_{3}}{n_{2}-n_{3}}, & n_{2} \leq x \leq n_{3} \\
0, & \text { other }
\end{array}\right.
$$

where $0 \leq n_{1} \leq n_{2} \leq n_{3}$.

Let $\widetilde{m}=\left(m_{1}, m_{2}, m_{3}\right)$ and $\widetilde{n}=\left(n_{1}, n_{2}, n_{3}\right)$ be fuzzy numbers. Then,

$$
\widetilde{m} \oplus \widetilde{n} \cong\left(m_{1}+n_{1}, m_{2}+n_{2}, m_{3}+n_{3}\right) .
$$

\subsection{The Entropy Weight Method}

With the premise that there are $m$ objects and $n$ criteria for evaluation, which form the evaluation matrix $Z=\left\{z_{i j} ; i=1,2, \ldots, m ; j=1,2, \ldots, n\right\}$, the weights of all criteria can be calculated through the entropy weight method [82], as shown in Equation (7). 


$$
\left\{\begin{array}{rl}
\omega_{j} & =\frac{1-H_{j}}{\sum_{i=1}^{n}\left(1-H_{j}\right)} \\
H_{j} & =\frac{\sum_{i=1}^{m} P_{i j} \ln \left(P_{i j}\right)}{z_{i j} \ln (m)} \\
P_{i j} & =\frac{z_{i=1}^{m} z_{i j}}{\sum_{i j}^{m}}
\end{array} .\right.
$$

\section{The Fuzzy Grey TOPSIS Method}

\subsection{Background}

Assume that there are $m$ objects to be evaluated. The objects set is $A=\left\{a_{1}, a_{2}, \ldots, a_{m}\right\}$. There are $p$ experts involved in the evaluation and decision. The experts set is denoted as $E=\left\{E_{1}, E_{2}, \ldots, E_{p}\right\}$.

To evaluate these objects, the experts should construct a reasonable and effective criterion system according to the feature of the considered problem and the purpose and preference of the decision-maker. As it is widely acknowledged, a real-life system usually contains some unknown information, i.e., it is a grey system. Therefore, some qualitative criteria need to be employed to evaluate the system. In addition, we also need a few quantitative criteria for some measurable aspects.

Assume that among $n$ criteria, some qualitative and some quantitative criteria are considered. The criterion set is $X=\left\{x_{1}, x_{2}, \ldots, x_{n}\right\}$. For the convenience of expression, assume that $x_{1}, x_{2}, \ldots, x_{i}$ are quantitative criteria and $x_{i+1}, \ldots, x_{n}$ are qualitative.

\subsection{The Procedure of Fuzzy Grey TOPSIS}

\section{Step 1: Find the evaluation data.}

Step1.1: Obtain evaluation data of qualitative criteria.

\subsubsection{Obtain the Fuzzy Linguistic Value and Transform it into Fuzzy Numbers}

To make the experts' evaluation more accurate, a set of fuzzy linguistic values is set up and noted as $\{$ Superb, Good, Normal, Bad, Terrible $\}$ ( $\{S, G, N, B, T\}$ for short). The evaluation data of qualitative criteria are given by experts in the form of fuzzy linguistic values that correspond to fuzzy numbers. Mapping rules are shown in Table 4.

Table 4. Mapping rules of linguistic variables and fuzzy numbers.

\begin{tabular}{cc}
\hline Superb (S) & $(0.8,0.9,0.9)$ \\
Good (G) & $(0.6,0.7,0.8)$ \\
Normal (N) & $(0.4,0.5,0.6)$ \\
Bad (B) & $(0.2,0.3,0.4)$ \\
Terrible (T) & $(0.1,0.1,0.2)$ \\
\hline
\end{tabular}

The linguistic variable evaluation matrixes are transformed as fuzzy number matrixes, as shown below.

$$
\widetilde{J}_{1}=\left[\begin{array}{ccc}
\widetilde{j}_{1(n-i+1)}^{1} & \cdots & \widetilde{j}_{1 n}^{1} \\
\vdots & \ddots & \vdots \\
\tilde{j}_{1(n-i+1)}^{k} & \cdots & \tilde{j}_{1 n}^{k}
\end{array}\right] \ldots \widetilde{J}_{m}=\left[\begin{array}{ccc}
\widetilde{j}_{m(n-i+1)}^{1} & \cdots & \widetilde{j}_{m n}^{1} \\
\vdots & \ddots & \vdots \\
\tilde{j}_{m(n-i+1)}^{k} & \cdots & \bar{j}_{m n}^{k}
\end{array}\right],
$$

where $\widetilde{J}_{i}$ represents the fuzzy number matrix of the $i$-th object $\widetilde{j}_{i j}^{k}$ represents the fuzzy number corresponding to the $k$-th expert's evaluation of the $i$-th object on the $j$-th criterion.

The fuzzy number evaluation values of $k$ experts need to be integrated into one fuzzy number according to Equation (6). The fuzzy evaluation matrix $\widetilde{J}$ can be given as 


$$
\widetilde{J}=\left[\begin{array}{ccc}
\widetilde{j}_{1(\mathrm{n}-\mathrm{i}+1)} & \cdots & \widetilde{j}_{1 n} \\
\vdots & \ddots & \vdots \\
\widetilde{j}_{m(\mathrm{n}-\mathrm{i}+1)} & \cdots & \tilde{j}_{m n}
\end{array}\right]
$$

where $\widetilde{j}_{i j}$ represents the fuzzy number of the $i$-th object on the $j$-th criterion.

\subsubsection{Defuzzify the Fuzzy Numbers}

The fuzzy numbers need to be defuzzified into numerical values to take part in the calculation procedure later. There are many defuzzification methods, each of which has its advantages and limits. Three methods are adopted in this paper. In the case that the operation is too simple, and its effectiveness cannot be verified [83], the mean value of the results of the three methods is taken. Fuzzy numbers $\widetilde{j_{i k}}=\left(a_{i k}, b_{i k}, c_{i k}\right)$ can be defuzzicated through the three methods stated as follows:

(1) Distance measure method [81]:

$$
M_{i k}^{1}=\frac{d_{i k}{ }^{-}}{d_{i k}{ }^{-}+d_{i k^{*}}} .
$$

If the optimal fuzzy evaluation value is defined as $\widetilde{j}_{i k}{ }^{*}=(1,1,1)$ and the worst fuzzy evaluation value is defined as $\widetilde{j}_{i k}{ }^{-}=(0,0,0)$, then

$$
\begin{gathered}
d_{i k}{ }^{-}=\sqrt{\frac{1}{4}\left(a_{i k}^{2}+2 b_{i k}^{2}+c_{i k}^{2}\right)}, \\
d_{i k}{ }^{*}=\sqrt{\frac{1}{4}\left[\left(1-a_{i k}\right)^{2}+2\left(1-b_{i k}\right)^{2}+\left(1-c_{i k}\right)^{2}\right]} .
\end{gathered}
$$

(2) Central value method [84]:

$$
\begin{gathered}
M_{i k}^{2}=b_{i k}+\frac{\left(c_{i k}-b_{i k}\right)-\left(b_{i k}-a_{i k}\right)}{6} \\
=\frac{4 b_{i k}+c_{i k}+a_{i k}}{6}
\end{gathered}
$$

(3) Gravity method [84]:

$$
M_{i k}^{3}=\left\{\begin{array}{cc}
a_{i k} & , a_{i k}=b_{i k}=c_{i k} \\
\frac{\left(c_{i k}\right)^{2}-\left(a_{i k}\right)^{2}+b_{i k}\left(c_{i k}-a_{i k}\right)}{3\left(c_{i k}-a_{i k}\right)} & , \text { otherwise }
\end{array} .\right.
$$

The numerical value $j_{i k}$ can be found by taking the mean value of the three results, i.e.,

$$
j_{i k}=\frac{M_{i k}^{1}+M_{i k}^{2}+M_{i k}^{3}}{3} .
$$

The fuzzy evaluation matrix $\widetilde{J}$ can be transformed into a numerical evaluation matrix $J^{*}$.

$$
J^{*}=\left[\begin{array}{ccc}
j_{1(n-i+1)} & \cdots & j_{1 n} \\
\vdots & \ddots & \vdots \\
j_{m(n-i+1)} & \cdots & j_{m n}
\end{array}\right]
$$




\section{Step1.2: Find evaluation data of quantitative criteria.}

The evaluation data of a few numerical criteria $\left\{j_{k 1}, j_{k 2}, \ldots, j_{k i} \mid k=1,2, \ldots, m\right\}$ are obtained through statistics and measurement methods. By seaming the numerical evaluation matrix of qualitative and quantitative criteria, the evaluation matrix $J$ can be found, as shown below,

$$
J=\left[\begin{array}{ccc}
j_{11} & \cdots & j_{1 n} \\
\vdots & \ddots & \vdots \\
j_{m 1} & \cdots & j_{m n}
\end{array}\right]
$$

where $J_{k l}$ represents the evaluation value of the $k$-th object on the $l$-th criterion, $k=1,2, \ldots, m, l=$ $1,2, \ldots, n$.

\section{Step 2: Standardize evaluation matrix.}

To eliminate the influence of dimension and order of magnitude, the evaluation matrix $J$ needs to be standardized according to Equation (14):

$$
c_{i k}=\frac{j_{i k}-\overline{j_{k}}}{S_{k}}
$$

where $\bar{j}_{k}$ is the mean and $S_{k}$ is the standard deviation of the evaluation values of the $k$-th criterion.

In that way, the standardized evaluation matrix $C$ can be found.

$$
C=\left[\begin{array}{ccc}
c_{11} & \cdots & c_{1 n} \\
\vdots & \ddots & \vdots \\
c_{m 1} & \cdots & c_{m n}
\end{array}\right]
$$

where $J_{k l}$ represents the standardized evaluation value of the $k$-th object on the $l$-th criterion, $k=$ $1,2, \ldots, m, l=1,2, \ldots, n$.

Theorem 1. The standardization transformation satisfies the following two axioms:

(1) Isotonicity:

$$
\text { If } j_{x k}<j_{y k} \text {, then } c_{x k}<c_{y k} \text {. If } j_{x k}>j_{y k} \text {, then } c_{x k}>c_{y k} \text {. }
$$

Proof. If $j_{x k}<j_{y k}$, then $j_{x k}-\overline{j_{k}}<j_{y k}-\overline{j_{k}}$. Thus $\frac{j_{x k}-\overline{j_{k}}}{S_{k}}<\frac{j_{y k}-\overline{j_{k}}}{S_{k}}$, namely, $c_{x k}<c_{y k}$. Similarly, if $j_{x k}>j_{y k}$ then $c_{x k}>c_{y k}$.

(2) Difference remaining:

$$
\forall x, y, p, q, \frac{j_{x k}-j_{y k}}{j_{p k}-j_{q k}}=\frac{c_{x k}-c_{y k}}{c_{p k}-c_{q k}}
$$

Proof. $\forall x, y, p, q, \frac{c_{x k}-c_{y k}}{c_{p k}-c_{q k}}$

$$
=\left(\frac{j_{x k}-\overline{j_{k}}}{S_{k}}-\frac{j_{y k}-\overline{j_{k}}}{S_{k}}\right) /\left(\frac{j_{p k}-\overline{j_{k}}}{S_{k}}-\frac{j_{q k}-\overline{j_{k}}}{S_{k}}\right)=\frac{j_{x k}-j_{y k}}{j_{p k}-j_{q k}} .
$$

\section{Step 3: Obtain weights of criteria.}

To aggregate the evaluation data, some series of weights that are reasonable and accurate as much as possible is certainly needed. The weights are considered in two aspects. On the one hand, the objective weights are calculated through the entropy weight method such that the influence of data 
can be considered. On the other hand, the subjective weights are given by the experts to express the decision preference. Finally, the weighted average value of objective and subjective weights is taken.

Step 3.1: Calculate objective weights of criteria.

The objective initial weights are mainly calculated through the entropy weight method. However, some minor amendments are made to make the formula meaningful. By using the data of standardized evaluation matrix $C=\left\{c_{i j}, i=1,2, \ldots, m, j=1,2, \ldots, n\right\}$, the objective weights vector $\omega^{1}=\left[\omega_{1}^{1}, \omega_{2}^{1}, \ldots, \omega_{n}^{1}\right]$ can be calculated according to Equation (15).

$$
\left\{\begin{aligned}
\omega_{j}^{1} & =\frac{1-H_{j}}{\sum_{j=1}^{n}\left(1-H_{j}\right)} \\
H_{j} & =\frac{\sum_{i=1}^{m}\left(1+P_{i j}\right) \ln \left(1+P_{i j}\right)}{c_{i j}-\ln (m)} . \\
P_{i j} & =\frac{c_{i=1}^{m}\left|c_{i j}\right|}{\sum_{i}^{m}} .
\end{aligned}\right.
$$

Step 3.2: Obtain subjective weights of criteria.

The subjective weights vector $\omega^{2}=\left[\omega_{1}^{2}, \omega_{2}^{2}, \ldots, \omega_{n}^{2}\right]$ is given by experts.

Step 3.3: Integrate objective and subjective weights.

The comprehensive weights vector $\omega^{0}=\left[\omega_{1}^{0}, \omega_{2}^{0}, \ldots, \omega_{n}^{0}\right]$ can be found according to Equation (16).

$$
\omega_{j}^{0}=\theta \omega_{j}^{1}+(1-\theta) \omega_{j}^{2}
$$

where the parameter $\theta \in(0,1)$ is determined by the decision maker according to the degree of trust in objective data and subjective judgment of experts. We set it as 0.5 in this paper.

Step 4: Identification of $\lambda$-fuzzy-measures.

It is generally believed that many interactions exist among criteria. If we integrate the evaluation matrix by weights only, the interactions are ignored, which will lead to an inadequate decision. Thus, the $\lambda$-fuzzy-measures are employed here to express the interactions.

Let us regard the comprehensive weights vector $\omega^{0}=\left[\omega_{1}^{0}, \omega_{2}^{0}, \ldots, \omega_{n}^{0}\right]$ as the fuzzy densities. The parameter $\lambda$ can be obtained by Equation (17):

$$
\frac{1}{\lambda}\left|\prod_{i=1}^{n}\left(1+\lambda \omega_{\mathrm{i}}^{0}\right)-1\right|=1 .
$$

Note that the comprehensive weights vector $\omega^{0}=\left[\omega_{1}^{0}, \omega_{2}^{0}, \ldots, \omega_{n}^{0}\right]$ and the parameter $\lambda$ are obtained. All the fuzzy-measures $\left\{\omega_{Q} ; Q \in P(X)\right\}$ can be calculated according to Equation (18), where $P(X)$ is the power set of $X$.

$$
\begin{aligned}
\omega_{Q} & =\sum_{i=1}^{p} \omega_{i}^{0}+\lambda \sum_{i_{1}=1}^{p-1} \sum_{i_{2}=i_{1}+1}^{p} \omega_{i_{1}}^{0} \omega_{i_{2}}^{0} \\
& +\ldots+\lambda^{p-1} \omega_{1}^{0} \omega_{2}^{0} \ldots \omega_{p}^{0}
\end{aligned}
$$

\section{Step 5: Calculate the grey fuzzy correlation degree.}

\section{Step 5.1: Calculate correlation coefficients.}

To describe the difference in shapes of all objects, their positive and the negative correlation coefficients need to be calculated. First of all, the positive and the negative ideal solution schemes $C^{+}=\left[c_{1}^{+}, c_{2}^{+}, \ldots, c_{n}^{+}\right]$and $C^{-}=\left[c_{1}^{-}, c_{2}^{-}, \ldots, c_{n}^{-}\right]$should be selected. With the premise that $J^{+}$represents the set of some criteria which are the bigger the better, and $J^{-}$represents the set of some criteria which are the smaller the better, the vector $C^{+}$and $C^{-}$can be determined according to Equations (19) and (20). 


$$
\begin{gathered}
c_{j}^{+}=\left\{\begin{array}{l}
\max _{1 \leq i \leq m}\left(c_{i j}\right), \text { if } j \in J^{+} \\
\min _{1 \leq i \leq m}\left(c_{i j}\right), \text { if } j \in J^{-}
\end{array},\right. \\
c_{j}^{-}=\left\{\begin{array}{l}
\min _{1 \leq i \leq m}\left(c_{i j}\right), \text { if } j \in J^{+} \\
\max _{1 \leq i \leq m}\left(c_{i j}\right), \text { if } j \in J^{-}
\end{array}\right.
\end{gathered}
$$

The positive correlation coefficients $\left\{\xi_{i j}^{+}, i=1,2, \ldots, m, j=1,2, \ldots, n\right\}$ and the negative correlation coefficients $\left\{\xi_{i j}^{-}, i=1,2, \ldots, m, j=1,2, \ldots, n\right\}$ of the $j$-th criterion can be calculated according to Equations (21) and (22):

$$
\begin{gathered}
\xi_{i j}^{+}=\frac{\operatorname{minmin}_{i}\left|c_{i j}^{+}-c_{i j}\right|+\rho \operatorname{maxmax}_{i}\left|c_{i j}^{+}-c_{i j}\right|}{\left|c_{i j}^{+}-c_{i j}\right|+\rho \operatorname{maxmax}_{i}\left|c_{i j}^{+}-c_{i j}\right|}, \\
\xi_{i j}^{-}=\frac{\operatorname{minmin}_{i}\left|c_{i j}^{-}-c_{i j}\right|+\rho \operatorname{maxmax}_{i}\left|c_{i j}^{-}-c_{i j}\right|}{\left|c_{i j}^{-}-c_{i j}\right|+\rho \operatorname{maxmax}_{i}\left|c_{i j}^{-}-c_{i j}\right|} .
\end{gathered}
$$

Then the positive correlation matrix $\xi^{+}$and the negative correlation matrix $\xi^{-}$can be obtained as

$$
\begin{aligned}
\xi^{+} & =\left[\begin{array}{ccc}
\xi_{11}^{+} & \ldots & \xi_{1 n}^{+} \\
\vdots & \ddots & \vdots \\
\xi_{m 1}^{+} & \cdots & \xi_{m n}^{+}
\end{array}\right] \\
\xi^{-} & =\left[\begin{array}{ccc}
\xi_{11}^{-} & \cdots & \xi_{1 n}^{-} \\
\vdots & \ddots & \vdots \\
\xi_{m 1}^{-} & \cdots & \xi_{m n}^{-}
\end{array}\right] .
\end{aligned}
$$

\section{Step 5.2: Calculate the grey fuzzy Choquet integral.}

To take the interactions among criteria into account, the Choquet fuzzy integral is used to integrate the correlation coefficients of every object. The positive grey fuzzy integral vector $R^{+}=\left[R_{1}^{+}, R_{2}^{+}, \ldots, R_{m}^{+}\right]$ and the negative grey fuzzy integral vector $R^{-}=\left[R_{1}^{-}, R_{2}^{-}, \ldots, R_{m}^{-}\right]$can be calculated as follows.

Definition 1. (Positive grey fuzzy Choquet integral): Let correlation coefficients $\left\{\xi_{i j}^{+} ; i=1,2, \ldots, m, j=1,2, \ldots, n\right\}$ be reordered in an ascending order such that $\xi_{i 1}^{+} \geq \ldots \geq \xi_{i j}^{+} \geq \ldots \geq \xi_{i n}^{+}$. The positive grey fuzzy Choquet integral of the $i$-th object is defined as

$$
\begin{aligned}
\mathrm{R}_{i}^{+} & =\xi_{i n}^{+} \omega_{12 \ldots . n}+\left[\xi_{i n-1}^{+}-\xi_{i n}^{+}\right] \omega_{12 \ldots(n-1)} \\
& +\ldots+\left[\xi_{i 1}^{+}-\xi_{i 2}^{+}\right] \omega_{1}
\end{aligned}
$$

where $\omega_{12 \ldots k}$ represents the weight of the set $\left\{x_{1}, x_{2}, \ldots, x_{k}\right\}(k \leq n)$ after rearrangement.

Definition 2. (Negative grey fuzzy Choquet integral): Let correlation coefficients $\left\{\xi_{i j}^{-} ; i=1,2, \ldots, m, j=1,2, \ldots, n\right\}$ be reordered in an ascending order such that $\xi_{i 1}^{-} \geq \ldots \geq \xi_{i j}^{-} \geq \ldots \geq \xi_{i n}^{-}$. The negative grey fuzzy Choquet integral of the $i$-th object is defined as

$$
\begin{aligned}
\mathrm{R}_{i}^{-} & =\xi_{i n}^{-} \omega_{12 \ldots n}+\left[\xi_{i n-1}^{-}-\xi_{i n}^{-}\right] \omega_{12 \ldots(n-1)} \\
& +\ldots+\left[\xi_{i 1}^{-}-\xi_{i 2}^{-}\right] \omega_{1}
\end{aligned}
$$




\section{Step 6: Calculate fuzzy distance to ideal solution.}

To embody the difference the in distance of all objects, the distance between all objects to the positive and negative ideal solution schemes should be obtained. The Choquet fuzzy integral should also be employed to amend the Euclidean distance such that the interactions can be expressed in the distance.

Definition 3. (Positive fuzzy ideal solution distance): Let positive distances of all criteria $\left\{d_{i j}^{+}=\left(c_{i j}-c_{j}^{+}\right)^{2} ; i=1,2, \ldots, m, j=1,2, \ldots, n\right\}$ be reordered in an ascending order such that $d_{i 1}^{+} \geq \ldots \geq$ $d_{i j}^{+} \geq \ldots \geq d_{i n}^{+}$. The positive fuzzy ideal solution distance of the $i$-th object is defined as

$$
\begin{aligned}
D_{i}^{+} & =\left[d_{i n}^{+} \omega_{12 \ldots n}+\left(d_{i n-1}^{+}-d_{i n}^{+}\right) \omega_{12 \ldots(n-1)} .\right. \\
& \left.+\ldots+\left(d_{i 1}^{+}-d_{i 2}^{+}\right) \omega_{1}\right]^{\frac{1}{2}}
\end{aligned}
$$

Definition 4. (Negative fuzzy ideal solution distance): Let negative distances of all criteria $\left\{d_{i j}^{-}=\left(c_{i j}-c_{j}^{-}\right)^{2} ; i=1,2, \ldots, m, j=1,2, \ldots, n\right\}$ be reordered in an ascending order such that $d_{i 1}^{-} \geq \ldots \geq$ $d_{i j}^{-} \geq \ldots \geq d_{i n}^{-}$. The positive ideal solution fuzzy distance of the $i$-th object is defined as

$$
\begin{aligned}
D_{i}^{-} & =\left[d_{i n}^{-} \omega_{12 \ldots n}+\left(d_{i n-1}^{-}-d_{i n}^{-}\right) \omega_{12 \ldots(n-1)} .\right. \\
& \left.+\ldots+\left(d_{i 1}^{-}-d_{i 2}^{-}\right) \omega_{1}\right]^{\frac{1}{2}}
\end{aligned}
$$

\section{Step 7: Get grey fuzzy TOPSIS.}

The positive grey fuzzy Choquet integral and the negative ideal solution distance depend on the close degree to the positive ideal solution of each scheme on the shape and distance, respectively. Their combination can represent the comprehensive close degree to the positive ideal solution of each scheme. Analogously, the combination of negative grey fuzzy Choquet integral and the positive ideal solution distance can characterize the close degree to the negative ideal solution of each scheme. To express the effects of $R^{+}, R^{-}, D^{+}$, and $D^{-}$, they need to be normalized before combination.

$$
N_{i}^{\text {new }}=\frac{N_{i}}{\max _{1 \leq i \leq m} N_{i}} ; i=1,2, \ldots, m,
$$

where $N_{i}$ represent $R^{+}\left(R^{-} ; D^{+} ; D^{-}\right)$, respectively.

For the conciseness, the normalized values of them are still denoted as $\mathrm{R}^{+}, \mathrm{R}^{-}, \mathrm{D}^{+}, \mathrm{D}^{-}$, respectively. The positive comprehensive proximity degree vector $\mathrm{S}^{+}=\left[\mathrm{S}_{1}^{+}, \mathrm{S}_{2}^{+}, \ldots, \mathrm{S}_{\mathrm{m}}^{+}\right]$and the negative comprehensive proximity degree vector $\mathrm{S}^{-}=\left[\mathrm{S}_{1}^{-}, \mathrm{S}_{2}^{-}, \ldots, \mathrm{S}_{\mathrm{m}}^{-}\right]$can be obtained by combining $\mathrm{R}^{+}, \mathrm{R}^{-}, \mathrm{D}^{+}$, and $\mathrm{D}^{-}$with a proper weight parameter $\mathrm{p}$ according to Equation (28).

$$
\left\{\begin{array}{l}
\mathrm{S}_{i}^{+}=p R_{i}^{+}+(1-p) D_{i}^{-} ; i=1,2, \ldots, m \\
\mathrm{~S}_{i}^{-}=p R_{i}^{-}+(1-p) D_{i}^{+} ; i=1,2, \ldots, m
\end{array}\right.
$$

where parameter $p \in(0,1)$ is determined by the decision-maker's preference.

The comprehensive evaluation vector $C S=\left[C S_{1}, C S_{2}, \ldots, C S_{m}\right]$ can be calculated by Equation (29).

$$
C S_{i}=\frac{S_{i}^{+}}{S_{i}^{-}+S_{i}^{+}} ; i=1,2, \ldots, m .
$$


The $m$ objects can be evaluated reasonably according to the comprehensive evaluation vector $C S=\left[C S_{1}, C S_{2}, \ldots, C S_{m}\right]$. The object whose comprehensive evaluation value is big is better than the one whose comprehensive evaluation value is small.

The flow chart of the proposed method is given in Figure 3.

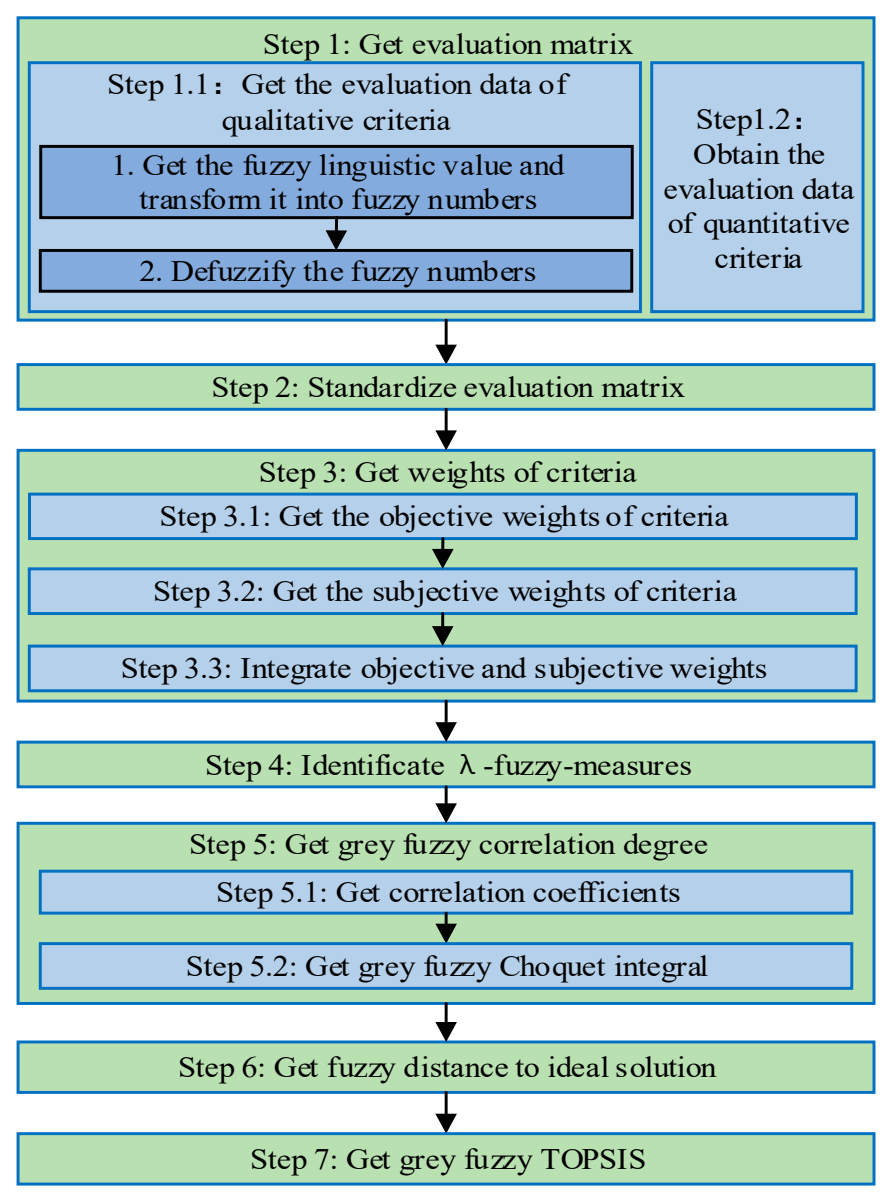

Figure 3. The flow chart of Grey Fuzzy TOPSIS.

\section{An Illustrative Example}

To verify the feasibility and effectiveness of the proposed method, an illustrative example of supplier evaluation of a collaborative manufacturing enterprise is given in this paper. The result was compared with GCE and TOPSIS. This example has six alternatives $A=\left\{A_{1}, A_{2}, A_{3}, A_{4}, A_{5}, A_{6}\right\}$ and 12 experts $E=\left\{E_{1}, E_{2}, \ldots, E_{12}\right\}$.

According to the feature of the supplier evaluation of the collaborative manufacturing enterprise and the purpose and preference of the decision-maker, a reasonable and effective criterion system was constructed by experts, as shown in Figure 4 . 


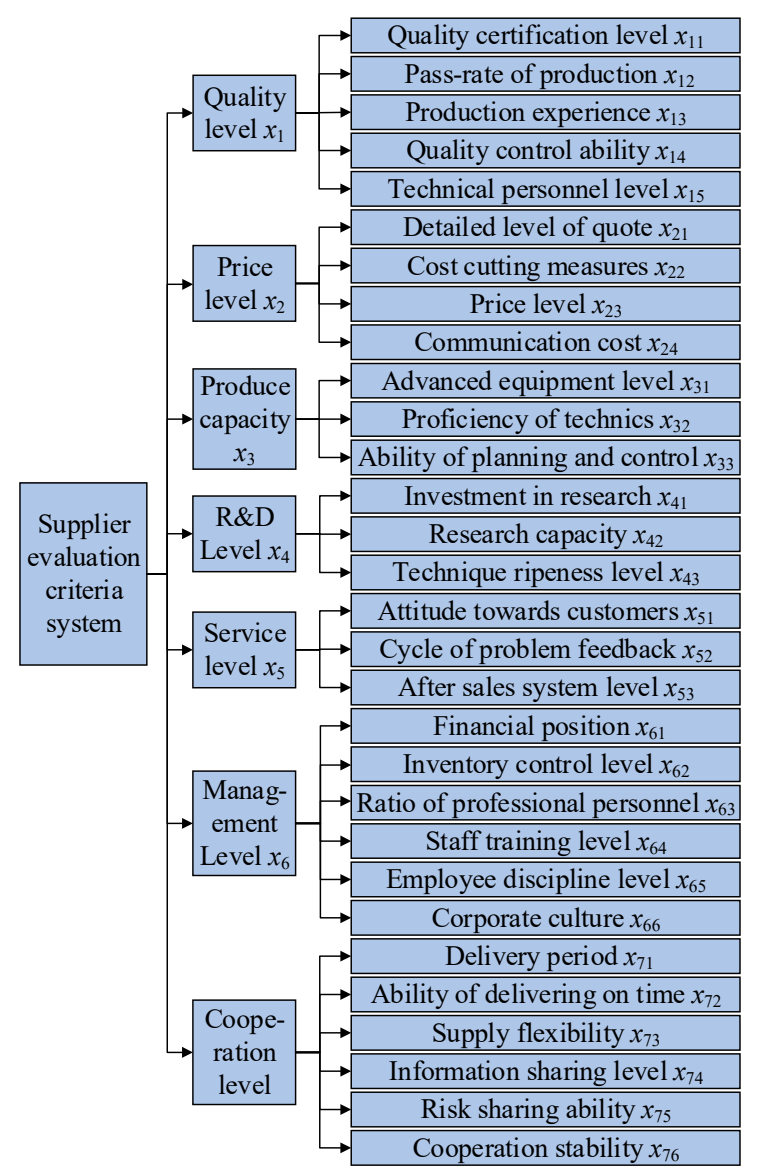

Figure 4. Supplier evaluation criterion system.

\subsection{Conducting the Proposed Method}

The detailed process of the proposed method to solve this example is illustrated below. Each level is addressed one by one. We illustrate the quality level in detail only for economy of space.

Step 1: Get the evaluation matrix.

The fuzzy linguistic value evaluation matrices $\left\{\tilde{j}_{1}, \widetilde{j_{2}}, \widetilde{j_{3}}, \widetilde{j_{4}}, \widetilde{j_{5}}, \widetilde{j}_{6}\right\}$ are shown as follows, in which the mapping rules of linguistic variables and fuzzy number are given in Table 4.

$$
\begin{aligned}
& \widetilde{J}_{1}=\left[\begin{array}{cccccccccccc}
S & S & G & S & S & G & S & S & S & G & S & S \\
0.98 & & & & & & & & & & & \\
G & N & G & G & N & N & G & G & G & S & G & G \\
S & G & S & S & S & S & N & G & G & S & G & S \\
G & G & S & G & G & S & G & S & S & G & S & S
\end{array}\right], \\
& \widetilde{J}_{2}=\left[\begin{array}{cccccccccccc}
B & B & B & T & T & B & B & B & B & T & B & B \\
0.83 & & & & & & & & & & & \\
N & N & N & G & N & N & N & G & N & N & G & G \\
N & G & G & N & G & S & G & G & G & G & N & G \\
G & G & G & S & G & G & G & G & S & G & N & G
\end{array}\right], \\
& \widetilde{J}_{3}=\left[\begin{array}{cccccccccccc}
S & S & G & S & S & S & G & G & S & G & S & S \\
0.92 & & & & & & & & & & & \\
N & N & N & G & N & N & N & G & N & B & N & N \\
N & N & N & B & N & B & B & B & N & N & N & B \\
N & N & N & B & N & N & N & G & G & N & N & N
\end{array}\right],
\end{aligned}
$$




$$
\begin{aligned}
\widetilde{J}_{4} & =\left[\begin{array}{cccccccccccc}
G & G & G & G & G & G & S & G & G & G & N & G \\
0.93 & & & & & & & & & & & \\
G & G & G & N & G & G & G & G & S & G & G & S \\
G & G & G & N & N & G & G & G & G & S & G & G \\
G & N & N & G & G & G & G & G & N & G & G & G
\end{array}\right], \\
\widetilde{J}_{5} & =\left[\begin{array}{cccccccccccc}
G & S & S & S & S & S & S & G & S & S & S & S \\
0.99 & & & & & & & & & & & \\
N & N & G & G & N & N & N & G & N & G & N & N \\
N & G & N & G & N & N & N & N & N & G & N & N \\
N & N & G & N & N & N & G & N & N & N & N & N
\end{array}\right], \\
\widetilde{J}_{6} & =\left[\begin{array}{ccllllllllll}
S & S & G & G & S & S & S & S & S & G & S & S \\
0.95 & & & & & & & & & & & \\
G & G & G & N & G & G & N & N & G & G & G & G \\
N & N & N & N & G & G & N & N & G & N & N & G \\
N & N & N & G & N & N & N & G & N & N & N & G
\end{array}\right],
\end{aligned}
$$

where each matrix represents the evaluation data of an alternative, and each row in the matrix represents the evaluation data of one qualitative criterion given by 12 experts expect for the second row of each matrix that is the evaluation data of the quantitative criterion and has just one value. In fact, we can give the evaluation of qualitative criteria and quantitative criteria, respectively, but for the convenience of writing, we give them in one matrix.

We transformed the fuzzy linguistic values into fuzzy numbers according to (6). Then these fuzzy numbers were aggregated according to Equation (6) and defuzzified according to Equations (8)-(13). Then the evaluation matrix $J$ was found as follows:

$$
J=\left[\begin{array}{lllll}
0.8295 & 0.9800 & 0.6635 & 0.7839 & 0.7858 \\
0.2579 & 0.8300 & 0.5662 & 0.6635 & 0.7111 \\
0.8150 & 0.9200 & 0.5166 & 0.4172 & 0.5166 \\
0.6965 & 0.9300 & 0.7111 & 0.6800 & 0.6489 \\
0.8440 & 0.9900 & 0.5662 & 0.5497 & 0.5331 \\
0.8295 & 0.9500 & 0.6489 & 0.5662 & 0.5497
\end{array}\right],
$$

where each row represents the evaluation data of an alternative, and each column represents the evaluation data of a criterion.

The 3-dimensional histogram of $J$ is portrayed in Figure 5.

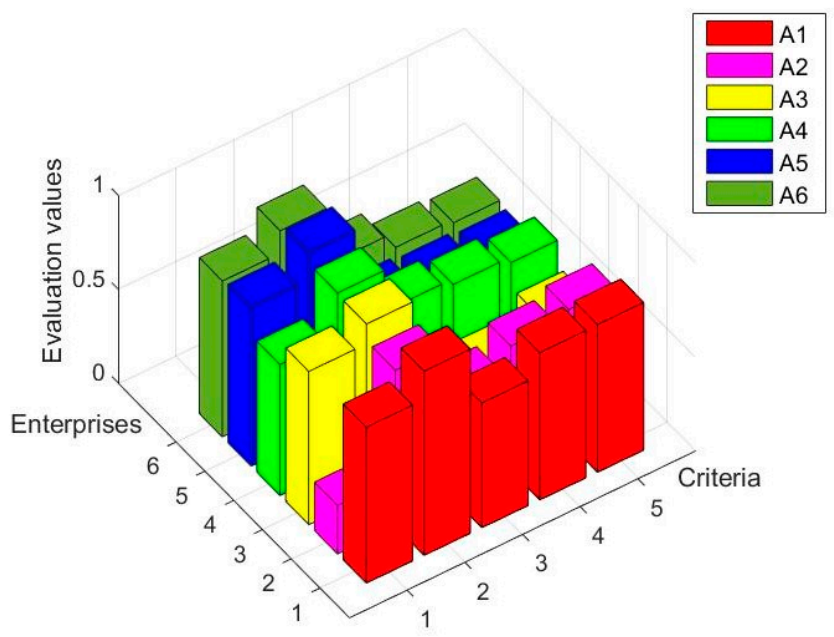

Figure 5. The 3-dimensional histograms of $J$. 
Step 2: Standardize evaluation matrix.

The evaluation matrix $J$ can be standardized as $C$ according to Equation (14), as shown as below.

$$
C=\left[\begin{array}{ccccc}
0.5129 & 0.8115 & 0.6977 & 1.3681 & 1.4790 \\
-1.9837 & -1.7970 & -0.6225 & 0.4202 & 0.7949 \\
0.4494 & -0.2319 & -1.2968 & -1.5178 & -0.9849 \\
-0.0679 & -0.0580 & 1.3439 & 0.5502 & 0.2263 \\
0.5763 & 0.9854 & -0.6225 & -0.4755 & -0.8334 \\
0.5129 & 0.2898 & 0.5002 & -0.3452 & -0.6819
\end{array}\right] .
$$

The 3-dimensional histograms of $C$ is depicted in Figure 6.

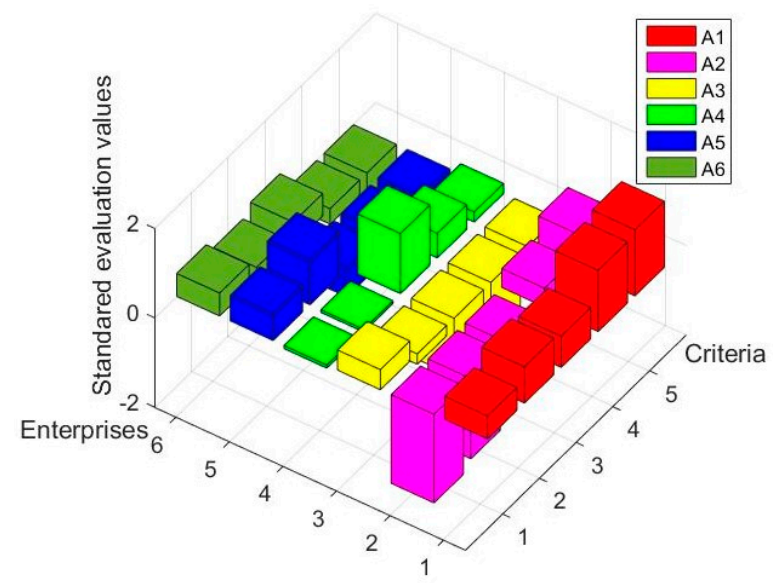

Figure 6. The 3-dimensional histograms of $C$.

\section{Step 3: Obtain weights of criteria.}

Step 3.1: Calculated the objective weights of criteria.

The objective weight vector which was calculated by Equation (15) on the standardized evaluation matrix was $\omega^{1}=[0.2216,0.2098,0.2159,0.1818,0.1709]$.

Step 3.2: Obtain the subjective weights of criteria.

The subjective weight vector which was given by experts was $\omega^{2}=$ [0.1990, 0.6040, 0.2080, 0.2990, 0.3100].

Step 3.3: Integrate objective and subjective weights.

The comprehensive weights vector can be obtained by combining the objective weights vector and the subjective weights vector according to Equation (16). It was $\omega^{0}=[0.2103,0.4069,0.2119,0.2404,0.2405]$.

Step 4: Identify $\lambda$-fuzzy-measures.

The parameter $\lambda$ is identified according to Equation (17), which was -0.5262 . The weights of all subsets of the power set of the criterion set can be calculated according to Equation (18), as shown in Table 5. 
Table 5. Fuzzy measures.

\begin{tabular}{cccccc}
\hline Sets & Measures & Sets & Measures & Sets & Measures \\
\hline 1 & 0.2103 & 2 & 0.4069 & 3 & 0.2119 \\
4 & 0.2404 & 5 & 0.2405 & 12 & 0.5722 \\
13 & 0.3988 & 14 & 0.4241 & 15 & 0.4242 \\
23 & 0.5734 & 24 & 0.5958 & 25 & 0.5959 \\
34 & 0.4255 & 35 & 0.4256 & 45 & 0.4504 \\
123 & 0.7203 & 124 & 0.7402 & 125 & 0.7402 \\
134 & 0.5888 & 135 & 0.5888 & 145 & 0.6109 \\
234 & 0.7413 & 235 & 0.7413 & 245 & 0.7609 \\
345 & 0.6121 & 1234 & 0.8696 & 1235 & 0.8696 \\
1245 & 0.8870 & 1345 & 0.7547 & 2345 & 0.8880 \\
12345 & 1.0000 & & & &
\end{tabular}

where $1,2,3,4$ represent the sets of $x_{11}, x_{12}, x_{13}$ and $x_{14}$, respectively (Similarly hereinafter).

Step 5: Calculate the grey fuzzy correlation degree.

Step 5.1: Calculate correlation coefficients.

Select $\left\{C^{+}\right\}=\{0.5763,0.9854,1.3439,1.3681,1.4790\}$ as the positive ideal solution scheme and $\left\{C^{-}\right\}=\{-1.9837,-1.7970,-1.2968,-1.5178,-0.9849\}$ as the negative ideal solution scheme. According to Equations (21) and (22), the positive correlation matrix $\xi^{+}$and the negative correlation matrix $\xi^{-}$ were found as follows.

$$
\begin{aligned}
\xi^{+} & =\left[\begin{array}{lllll}
0.9579 & 0.8924 & 0.6907 & 1.0000 & 1.0000 \\
0.3605 & 0.3415 & 0.4232 & 0.6035 & 0.6784 \\
0.9192 & 0.5424 & 0.3533 & 0.3333 & 0.3693 \\
0.6914 & 0.5803 & 1.0000 & 0.6383 & 0.5353 \\
1.0000 & 1.0000 & 0.4232 & 0.4391 & 0.3842 \\
0.9579 & 0.6747 & 0.6310 & 0.4572 & 0.4004
\end{array}\right], \\
\xi^{-} & =\left[\begin{array}{lllll}
0.3663 & 0.3562 & 0.4198 & 0.3333 & 0.3693 \\
1.0000 & 1.0000 & 0.6815 & 0.4268 & 0.4477 \\
0.3723 & 0.4797 & 1.0000 & 1.0000 & 1.0000 \\
0.4296 & 0.4535 & 0.3533 & 0.4110 & 0.5437 \\
0.3605 & 0.3415 & 0.6815 & 0.5806 & 0.9050 \\
0.3663 & 0.4088 & 0.4454 & 0.5517 & 0.8265
\end{array}\right] .
\end{aligned}
$$

Step 5.2: Calculated grey fuzzy Choquet integral.

The positive and negative grey fuzzy integral vectors can be obtained by applying Equations (23) and (24) on the correlation matrix and the comprehensive weights vector which, respectively, were $R^{+}=$ $[1.0000,0.5314,0.5824,0.7486,0.8085,0.7103]$ and $R^{-}=[0.4665,1.0000,0.9881,0.5708,0.7381,0.6792]$.

Step 6: Calculate fuzzy distance to ideal solution.

The positive and negative ideal solution distance vectors can be calculated by applying Equations (25), (26) on the standardized evaluation matrix and the comprehensive weights vector, which, respectively, were $D^{+}=[0.1119,0.7536,0.7771,0.3408,1.0000,0.9583]$ and $D^{-}=[0.4690,0.3669,0.4180,0.4585,1.0000,0.9597]$.

Step 7: Calculate the comprehensive proximity degree.

Normalize $\mathrm{R}^{+}, \mathrm{R}^{-}, \mathrm{D}^{+}, \mathrm{D}^{-}$according to Equation (27). Set the parameter $\mathrm{p}$ as 0.5 , which means the importance of shape and distance is the same. The positive and negative comprehensive proximity degree vectors can be calculated by applying Equation (28) on the grey fuzzy integral vector and the ideal solution distance vector, which, respectively, were $S^{+}=[0.7345,0.4491,0.5002,0.6036,0.9043,0.8350]$ and $S^{-}=[0.2892,0.8768,0.8826,0.4558,0.8691,0.8188]$.

The final comprehensive evaluation vector can be obtained by aggregating the positive and negative comprehensive proximity degree vector according to Equation (29) which was $C S=[0.7175,0.3387,0.3617,0.5697,0.5099,0.5049]$. The sequence of objects was $1>4>5>6>3>2$. 
Intuitively, Figure 6 shows that enterprise 1 performed very well on all criteria; while enterprise 2 performed very badly on all criteria. Enterprise 4 performed averagely on criteria 1, 2, 4, and 5 but performed excellently on criterion 3 . Enterprises 5,6 , and 3 all performed averagely and enterprise 5 performed slightly better than enterprise 6 , and enterprise 6 performed slightly better than enterprise 3 on most criteria. The sequence coincided with our intuitionistic judgment.

The bar chart of $R^{+}, R^{-}, D^{+}$, and $D^{-}$is depicted in Figure 7. It shows that the values of $R^{+}, R^{-}, D^{+}$, and $D^{-}$were not coincident. If we concentrate on different aspects, we can obtain different evaluation results.

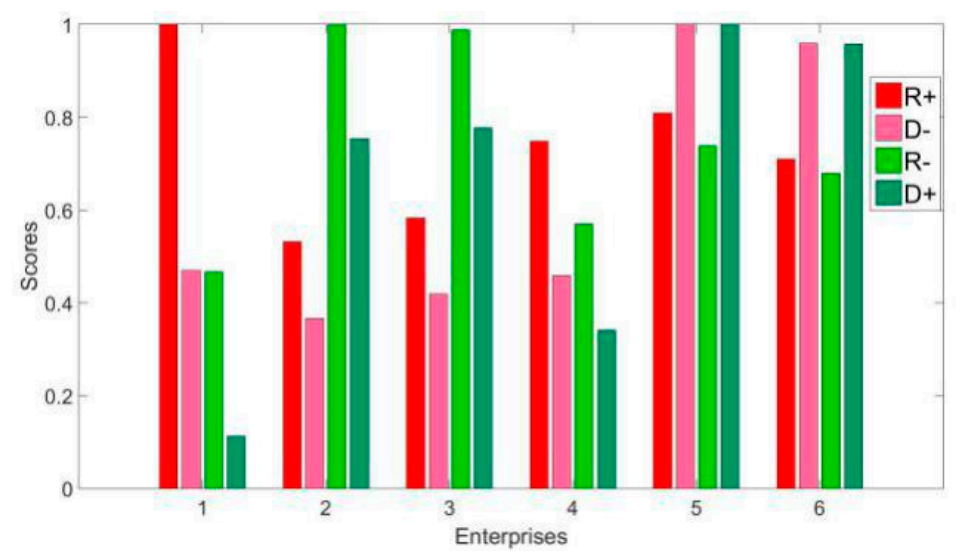

Figure 7. Bar chart of $R^{+}, R^{-}, D^{+}, D^{-}$.

\subsection{Comparisons and Sensitivity Analysis}

To compare the effects of the proposed method with the existing methods, the result of GCE and TOPSIS is given below.

By standardizing $w^{0}$, the weights of GCE can be obtained. The absolute correlation degree (ACD) can be calculated according to the weights and the positive correlation matrix. The ideal solution distance $D_{\text {TOPSIS }}^{+}$and $D_{\text {TOPSIS }}^{-}$can be found by the standardized evaluation matrix. The relative closeness degree (RCD) can be obtained through $D_{\text {TOPSIS }}^{+}$and $D_{\text {TOPSIS }}^{-}$.

To carry out a sensitivity analysis of parameter $p$, a series of experiments was conducted and the value of $p$ was between 0 and 1 , and the interval was 0.2 . The result is shown in Table 6 and Figure 8 .

\subsection{Result Analysis}

Table 6 and Figure 8 show that the sequence sorted according to GCE was always $1>5>4>6>$ $3>2$ while the sequence sorted due to TOPSIS was always $1>4>6>5>3>2$. The result means that enterprise 4 is bad in terms of shape but good in terms of distance since it performed well on criterion 3 but badly on criteria 1 and 2. Enterprise 5 is bad in terms of distance, but good in terms of shape since it performed slightly better than average on most criteria, which is similar to enterprise 1 .

The sequence sorted according to FGT is slightly related to parameter $p$. When $p=0$, the sequence was $1>4>5>6>2>3$. when $p>0$, the sequence was $1>4>5>6>3>2$. Enterprise 2 has slight advantages on distance, since it performed barely satisfactorily on criteria 4 and 5 . However, its performance was instable. When the factor of shape is taken into consideration, enterprise 3 will be better than enterprise 2. Figure 8 clearly shows that the comprehensive evaluation value of enterprise $1\left(C S_{1}\right)$ obviously decreased, $C S_{4}$ slightly decreased, $C S_{2}, C S_{3}$, and $C S_{5}$ obviously increased, and $C S_{6}$ slightly increased with the increase of parameter $p$, i.e., the increase consideration of shape.

The result shows that the proposed method can reflect both the difference of shape and distance of objects, which overcomes the one-sidedness of the GCE method and TOPSIS method. 
Table 6. The result of sensitivity analysis.

\begin{tabular}{ccccccccc}
\hline & $\mathbf{p}$ & $\mathbf{A 1}$ & $\mathbf{A 2}$ & $\mathbf{A 3}$ & $\mathbf{A 4}$ & $\mathbf{A 5}$ & $\mathbf{A 6}$ & Sequence \\
\hline CS & 0 & 0.8073 & 0.3274 & 0.3498 & 0.5737 & 0.5000 & 0.5003 & $1,4,6,5,3,2$ \\
ACD & 0 & 0.9097 & 0.4677 & 0.5022 & 0.6684 & 0.6907 & 0.6228 & $1,5,4,6,3,2$ \\
RCD & 0 & 0.8929 & 0.3807 & 0.3769 & 0.6949 & 0.5286 & 0.5685 & $1,4,6,5,2,3$ \\
CS & 0.2 & 0.7588 & 0.3324 & 0.3550 & 0.5718 & 0.5037 & 0.5020 & $1,4,5,6,2,3$ \\
ACD & 0.2 & 0.9097 & 0.4677 & 0.5022 & 0.6684 & 0.6907 & 0.6228 & $1,5,4,6,3,2$ \\
RCD & 0.2 & 0.8929 & 0.3807 & 0.3769 & 0.6949 & 0.5286 & 0.5685 & $1,4,6,5,2,3$ \\
CS & 0.4 & 0.7286 & 0.3368 & 0.3596 & 0.5704 & 0.5077 & 0.5039 & $1,4,5,6,3,2$ \\
ACD & 0.4 & 0.9098 & 0.4677 & 0.5022 & 0.6684 & 0.6907 & 0.6228 & $1,5,4,6,3,2$ \\
RCD & 0.4 & 0.8929 & 0.3807 & 0.3769 & 0.6949 & 0.5286 & 0.5685 & $1,4,6,5,2,3$ \\
CS & 0.6 & 0.7081 & 0.3406 & 0.364 & 0.5692 & 0.5122 & 0.5060 & $1,4,5,6,3,2$ \\
ACD & 0.6 & 0.9098 & 0.4677 & 0.5022 & 0.6684 & 0.6907 & 0.6228 & $1,5,4,6,3,2$ \\
RCD & 0.6 & 0.8929 & 0.3807 & 0.3769 & 0.6949 & 0.5286 & 0.5685 & $1,4,6,5,2,3$ \\
CS & 0.8 & 0.6932 & 0.3440 & 0.3675 & 0.5682 & 0.5172 & 0.5084 & $1,4,5,6,3,2$ \\
ACD & 0.8 & 0.9098 & 0.4677 & 0.5022 & 0.6684 & 0.6907 & 0.6228 & $1,5,4,6,3,2$ \\
RCD & 0.8 & 0.8929 & 0.3807 & 0.3769 & 0.6949 & 0.5286 & 0.5685 & $1,4,6,5,2,3$ \\
CS & 1 & 0.6819 & 0.3470 & 0.3708 & 0.5674 & 0.5228 & 0.5112 & $1,4,5,6,3,2$ \\
ACD & 1 & 0.9098 & 0.4677 & 0.5022 & 0.6684 & 0.6907 & 0.6228 & $1,5,4,6,3,2$ \\
RCD & 1 & 0.8929 & 0.3807 & 0.3769 & 0.6949 & 0.5286 & 0.5685 & $1,4,6,5,2,3$ \\
\hline
\end{tabular}

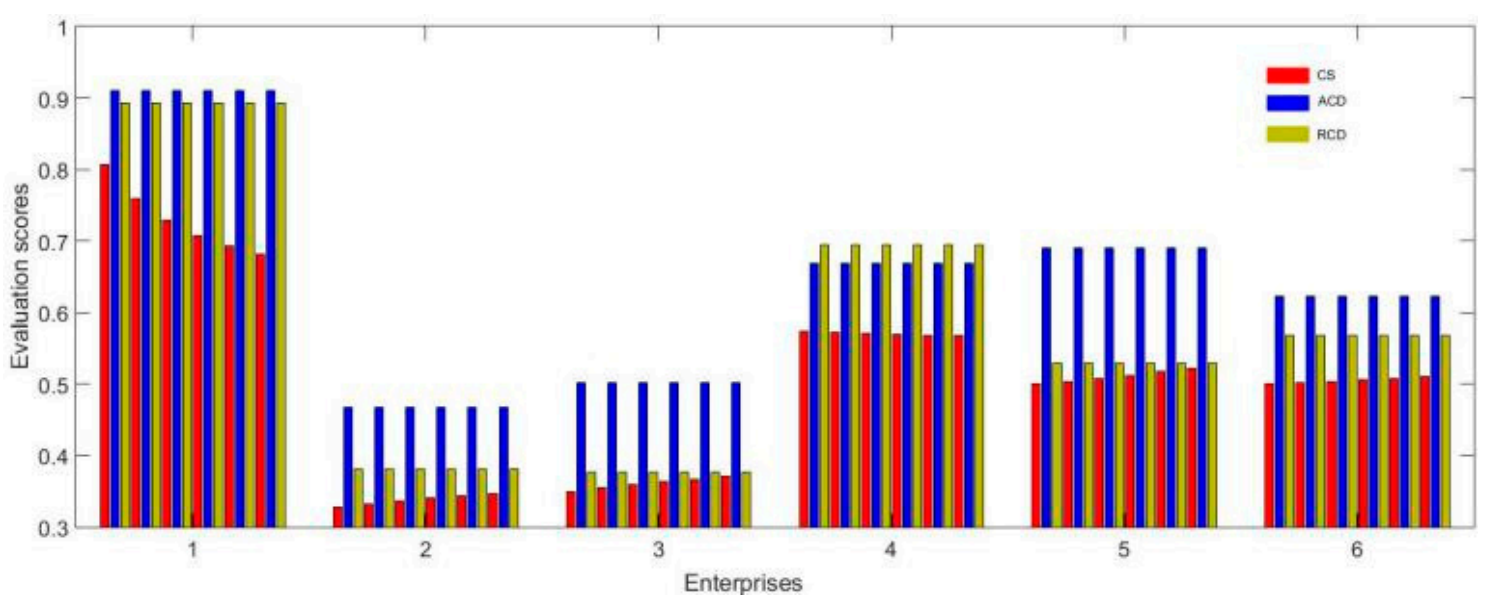

Figure 8. The result of sensitivity analysis.

\section{Conclusions}

Generally speaking, the MCDM problems are essential in modern society for businesses and private individuals. The existing MCDM methods, such as GCE and TOPSIS, have some disadvantages which cannot take the interaction of criteria into consideration. In the view of this, a novel MCDM method that combines the GCE, TOPSIS, and fuzzy integral, called the fuzzy grey TOPSIS, was proposed to improve the deficiency mentioned above. The effectiveness of the proposed method was verified by the illustrative example of supplier evaluation of a collaborative manufacturing enterprise as well as some sensitivities.

There are some recommendations for future studies. One idea is to focus on other types of fuzzy numbers and correlation coefficients and even redefine them. We will compare them by conducting more experiments and refine the proposed method [85-87]. As such, hybridizing the proposed MCDM method with recent advances in heuristics and metaheuristics is another good continuation of this work [88-93].

Author Contributions: Conceptualization, G.T. and J.T.; Methodology, N.H. and Z.L.; Hardware and software, A.M.F.-F. and Z.Z.; Writing and validation, Y.F., Z.Z. and W.W. 
Funding: This work was supported by the Science Fund for Creative Research Groups of National Natural Science Foundation of China (No. 51821093), the National Natural Science Foundation of China (Nos. 51935009 and 51775238), and Zhejiang Provincial Natural Science Foundation of China (No. LZ18E050001).

Acknowledgments: Sincere appreciation is extended to the reviewers of this paper for their helpful comments.

Conflicts of Interest: The authors declare no conflict of interest.

Notations and Nomenclature:

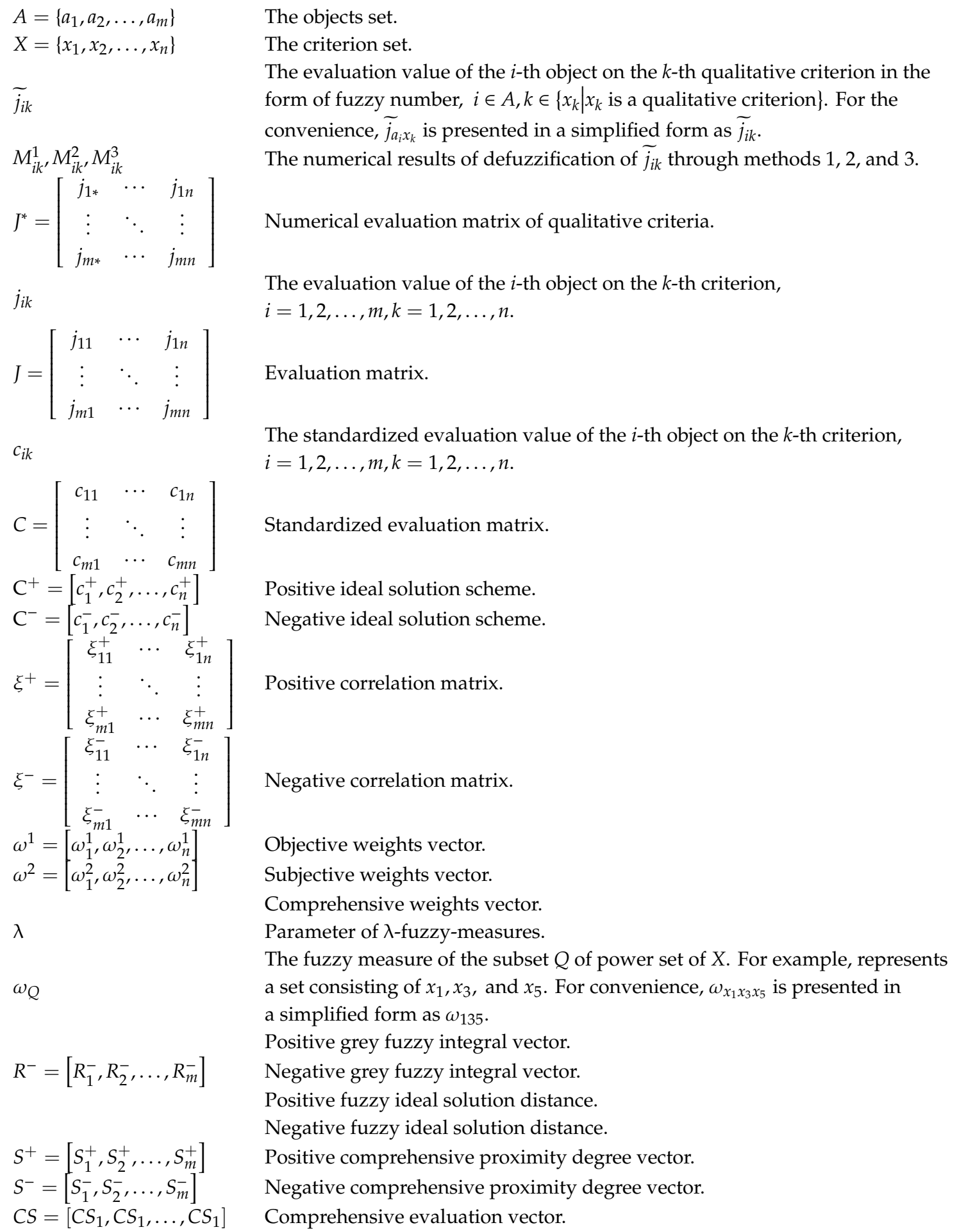

The objects set.

The criterion set.

The evaluation value of the $i$-th object on the $k$-th qualitative criterion in the form of fuzzy number, $i \in A, k \in\left\{x_{k} \mid x_{k}\right.$ is a qualitative criterion $\}$. For the convenience, $\widetilde{j}_{a_{i} x_{k}}$ is presented in a simplified form as $\widetilde{j_{i k}}$.

The numerical results of defuzzification of $\widetilde{j_{i k}}$ through methods 1,2 , and 3.

Numerical evaluation matrix of qualitative criteria.

The evaluation value of the $i$-th object on the $k$-th criterion,

$i=1,2, \ldots, m, k=1,2, \ldots, n$.

Evaluation matrix.

The standardized evaluation value of the $i$-th object on the $k$-th criterion, $i=1,2, \ldots, m, k=1,2, \ldots, n$.

Standardized evaluation matrix

Positive ideal solution scheme.

Negative ideal solution scheme.

Positive correlation matrix.

Negative correlation matrix.

Objective weights vector.

Subjective weights vector.

Comprehensive weights vector.

Parameter of $\lambda$-fuzzy-measures.

The fuzzy measure of the subset $Q$ of power set of $X$. For example, represents a set consisting of $x_{1}, x_{3}$, and $x_{5}$. For convenience, $\omega_{x_{1} x_{3} x_{5}}$ is presented in a simplified form as $\omega_{135}$.

Positive grey fuzzy integral vector.

Negative grey fuzzy integral vector.

Positive fuzzy ideal solution distance.

Negative fuzzy ideal solution distance.

Positive comprehensive proximity degree vector.

Negative comprehensive proximity degree vector.

Comprehensive evaluation vector. 


\section{References}

1. Gumus, S.; Egilmez, G.; Kucukvar, M.; Shin Park, Y. Integrating expert weighting and multi-criteria decision making into eco-efficiency analysis: The case of US manufacturing. J. Oper. Res. Soc. 2016, 67, 616-628. [CrossRef]

2. Xue, Y.X.; You, J.X.; Zhao, X.; Liu, H.C. An integrated linguistic MCDM approach for robot evaluation and selection with incomplete weight information. Int. J. Prod. Res. 2016, 110, 1-16. [CrossRef]

3. Shen, K.Y.; Hu, S.K.; Tzeng, G.H. Financial modeling and improvement planning for the life insurance industry by using a rough knowledge based hybrid MCDM model. Inf. Sci. 2017, 375, 296-313. [CrossRef]

4. Govindan, K.; Kannan, D.; Shankar, M. Evaluation of green manufacturing practices using a hybrid mcdm model combining danp with promethee. Int. J. Prod. Res. 2015, 53, 1-28. [CrossRef]

5. Liou, J.J.; Tamošaitienė, J.; Zavadskas, E.K.; Tzeng, G.H. New hybrid COPRAS-G MADM model for improving and selecting suppliers in green supply chain management. Int. J. Prod. Res. 2015, 263, 1-21. [CrossRef]

6. Wang, Y.M.; Parkan, C. A preemptive goal programming method for aggregating OWA operator weights in group decision making. Inf. Sci. 2007, 177, 1867-1877. [CrossRef]

7. Tsai, P.F.; Lin, F.M. An application of multi-attribute value theory to patient-bed assignment in hospital admission management: An empirical study. J. Healthc. Eng. 2014, 5, 439-456. [CrossRef] [PubMed]

8. Torrance, G.W.; Boyle, M.H.; Horwood, S.P. Application of multi-attribute utility theory to measure social preferences for health states. Oper. Res. 1982, 30, 1043-1069. [CrossRef]

9. Wang, X.; Chen, X.; Hu, H.; Yu, K.; Li, Z. Research on self-healing restoration strategy of urban power grid based on multi-agent technology. In 2011 International Conference on Advanced Power System Automation and Protection; IEEE: Piscatville, NJ, USA, 2011; pp. 1215-1218.

10. Saaty, T.L. Decision making with the analytic hierarchy process. Int. J. Serv. Sci. 2008, 1, 83-98. [CrossRef]

11. Cook, W.D. Data envelopment analysis: A comprehensive text with models, applications, references and DEA-solver software. J. Oper. Res. Soc. 2001, 52, 1408-1409.

12. Boran, F.E.; Genç, S.; Kurt, M.; Akay, D. A multi-criteria intuitionistic fuzzy group decision making for supplier selection with TOPSIS method. Expert Syst. Appl. 2009, 36, 11363-11368. [CrossRef]

13. Tian, G.D.; Zhang, H.H.; Feng, Y.; Jia, H.; Zhang, C.; Jiang, Z.; Li, Z.; Li, P. Operation patterns analysis of automotive components remanufacturing industry development in China. J. Clean. Prod. 2017, 64, 1363-1375. [CrossRef]

14. Huang, K.; Chen, S.F.; Sun, Y.; Qi, X. Study and implementation on the grey comprehensive evaluation support system of ecocity. J. Southeast Univ. (Engl. Ed.) 2002, 18, 356-360.

15. Gong, L.; Jin, C. Fuzzy comprehensive evaluation for carrying capacity of regional water resources. Water Resour. Manag. 2009, 23, 2505-2513. [CrossRef]

16. Hopfield, J.J. Artificial neural networks. IEEE Circuits Devices Mag. 1988, 4, 3-10. [CrossRef]

17. Pati, N.; Sahu, A.K.; Datta, S.; Mahapatra, S.S. Evaluation and selection of suppliers considering green perspectives: Comparative analysis on application of FMLMCDM and fuzzy-TOPSIS. Benchmarking 2016, 23, 1579-1604.

18. Mousavi, S.M.; Torabi, S.A.; Tavakkoli-Moghaddam, R. A hierarchical group decision-making approach for new product selection in a fuzzy environment. Arab. J. Sci. Eng. 2013, 38, 3233-3248. [CrossRef]

19. Mousavi, S.M.; Jolai, F.; Tavakkoli-Moghaddam, R.; Vahdani, B. A fuzzy grey model based on the compromise ranking for multi-criteria group decision making problems in manufacturing systems. J. Intell. Fuzzy Syst. 2013, 24, 819-827.

20. Mousavi, S.M.; Vahdani, B.; Tavakkoli-Moghaddam, R.; Tajik, N. Soft computing based on a fuzzy grey compromise solution approach with an application to the selection problem of material handling equipment. Int. J. Comput. Integr. Manuf. 2014, 27, 547-569. [CrossRef]

21. Mousavi, S.M.; Mirdamadi, S.; Siadat, A.; Dantan, J.; Tavakkoli-Moghaddam, R. An intuitionistic fuzzy grey model for selection problems with an application to the inspection planning in manufacturing firms. Eng. Appl. Artif. Intell. 2015, 39, 157-167. [CrossRef]

22. Mousavi, S.M.; Vahdani, B. Cross-docking location selection in distribution systems: A new intuitionistic fuzzy hierarchical decision model. Int. J. Comput. Intell. Syst. 2016, 9, 91-109. [CrossRef]

23. Hashemi, H.; Bazargan, J.; Mousavi, S.M. A compromise ratio method with an application to water resources management: An intuitionistic fuzzy set. Water Resour. Manag. 2013, 27, 2029-2051. [CrossRef] 
24. Shukla, V.; Auriol, G. Hipel, K.W. Multicriteria decision-making methodology for systems engineering. IEEE Syst. J. 2016, 10, 4-14. [CrossRef]

25. Huang, E.; Zhang, S.; Lee, L.H.; Chew, E.P.; Chen, C.H. Improving analytic hierarchy process expert allocation using optimal computing budget allocation. IEEE Trans. Syst. Man Cybern. Syst. 2016, 46, 1140-1147. [CrossRef]

26. Kuang, H.B.; Bashar, M.A.; Hipel, K.W.; Kilgour, D.M. Grey-based preference in a graph model for conflict resolution with multiple decision makers. IEEE Trans. Syst. Man Cybern. Syst. 2015, 45, 1254-1267. [CrossRef]

27. Özpeynirci, Ö.; Özpeynirci, S.; Kaya, A. An interactive approach for multiple criteria selection problem. Compu. Oper. Res. 2017, 78, 154-162. [CrossRef]

28. Zhou, Q.; Shi, P.; Liu, H.; Xu, S. Neural-network-based decentralized adaptive output-feedback control for large-scale stochastic nonlinear systems. IEEE Trans. Syst. Man Cybern. Part B Cybern. 2012, 42, 1608-1619. [CrossRef] [PubMed]

29. Mohamed, A.A.M. An interactive Bi-criteria heuristic algorithm for the coherent system assembly. In 2014 IEEE International Conference on Industrial Engineering and Engineering Management; IEEE: Piscatville, NJ, USA, 2015; Volume 25, pp. 49-53.

30. Liao, H.; Xu, Z.; Zeng, X.J. Hesitant fuzzy linguistic vikor method and its application in qualitative multiple criteria decision making. IEEE Trans. Fuzzy Syst. 2015, 23, 1343-1355. [CrossRef]

31. Tehrani, A.F.; Cheng, W.W.; Hullermeier, E. Preference learning using the Choquet integral: The case of multipartite ranking. IEEE Trans. Fuzzy Syst. 2012, 20, 1102-1113. [CrossRef]

32. Su, X.; Wu, L.; Shi, P.; Song, Y.D. H-infinity model reduction of takagi-sugeno fuzzy stochastic systems. IEEE Trans. Syst. Man Cybern. Part B Cybern. 2012, 42, 1574-1585.

33. Meng, F.; Chen, X.; Zhang, Q. Induced generalized hesitant fuzzy Shapley hybrid operators and their application in multi-attribute decision making. Appl. Soft Comput. 2015, 28, 599-607. [CrossRef]

34. Wu, Y.; Geng, S.; Xu, H.; Zhang, H. Study of decision framework of wind farm project plan selection under intuitionistic fuzzy set and fuzzy measure environment. Energy Convers. Manag. 2014, 87, 274-284. [CrossRef]

35. Sugeno, M. Fuzzy measure and fuzzy integral. Trans. Soc. Instrum. Control Eng. 1972, 2, 218-226. [CrossRef]

36. Mesiar, R.; Mesiarova-Zemenkova, A. Ahmad, K. Level-dependent Sugeno integral. IEEE Trans. Fuzzy Syst. 2009, 17, 167-172. [CrossRef]

37. Hu, Y.C.; Chen, H.C. Choquet integral-based hierarchical networks for evaluating customer service perceptions on fast food stores. Expert Syst. Appl. 2010, 37, 7880-7887. [CrossRef]

38. Wang, X.Z. Fuzzy Measure and Fuzzy Integral and Its Application in Classifier Technology; Science Publishing Company: Beijing, China, 2008. (In Chinese)

39. He, Q.; Chen, J.F.; Yuan, X.Q.; Li, J. Choquet fuzzy integral aggregation based on g-lambda fuzzy measure. In 2007 International Conference on Wavelet Analysis and Pattern Recognition; IEEE: Piscatville, NJ, USA, 2007; pp. 98-102.

40. Dymova, L.; Sevastjanov, P.; Tikhonenko, A. An interval type-2 fuzzy extension of the topsis method using alpha cuts. Knowl. Based Syst. 2015, 83, 116-127. [CrossRef]

41. Xia, X.; Sun, Y.; Wu, K.; Jiang, Q. Optimization of a straw ring-die briquetting process combined analytic hierarchy process and grey correlation analysis method. Fuel Process. Technol. 2016, 152, 303-309. [CrossRef]

42. Bouzarour-Amokrane, Y.; Tchangani, A.; Peres, F. A bipolar consensus approach for group decision making problems. Expert Syst. Appl. 2015, 42, 1759-1772. [CrossRef]

43. Tchangani, A.P. Bipolar aggregation method for fuzzy nominal classification using Weighted Cardinal Fuzzy Measure (WCFM). J. Uncertain Syst. 2013, 7, 138-151.

44. Zhang, H.H.; Peng, Y.; Hou, L.; Tian, G.D.; Li, Z.W. A hybrid multi-objective optimization approach for energy-absorbing structures in train collisions. Inf. Sci. 2019, 481, 491-506. [CrossRef]

45. Mousavi-Nasab, S.H.; Sotoudeh-Anvari, A. A new multi-criteria decision making approach for sustainable material selection problem: A critical study on rank reversal problem. J. Clean. Prod. 2018, 182, 466-484. [CrossRef] 
46. Hassan, M.N.; Hawas, Y.E.; Ahmed, K. A multi-dimensional framework for evaluating the transit service performance. Trans. Res. Part A Policy Pract. 2013, 50, 47-61. [CrossRef]

47. Kazançoğlu, Y.; Kazançoğlu, İ. Benchmarking service quality performance of airlines in Turkey. Eskişehir Osman. Üniversitesi İktis. ve İdari Bilim. Derg. 2013, 8, 59-91.

48. Bagočius, V.; Zavadskas, E.K.; Turskis, Z. Selecting a location for a liquefied natural gas terminal in the Eastern Baltic Sea. Transport 2014, 29, 69-74. [CrossRef]

49. Yayla, A.Y.; Oztekin, A.; Gumus, A.T.; Gunasekaran, A. A hybrid data analytic methodology for 3PL transportation provider evaluation using fuzzy multi-criteria decision making. Int. J. Prod. Res. 2015, 53, 6094-6113. [CrossRef]

50. John, A.; Yang, Z.; Riahi, R.; Wang, J. Application of a collaborative modelling and strategic fuzzy decision support system for selecting appropriate resilience strategies for seaport operations. J. Traffic Trans. Eng. 2014, 1, 159-179. [CrossRef]

51. Shanian, A.; Savadogo, O. TOPSIS multiple-criteria decision support analysis for material selection of metallic bipolar plates for polymer electrolyte fuel cell. J. Power Source 2006, 159, 1095-1104. [CrossRef]

52. Olson, D.L. Comparison of weights in TOPSIS models. Math. Comput. Model. 2004, 40, 721-727. [CrossRef]

53. Deng, H.; Yeh, C.H.; Willis, R.J. Inter-company comparison using modified TOPSIS with objective weights. Comput. Oper. Res. 2000, 27, 963-973. [CrossRef]

54. Buyukozkan, G.; Cifci, G. A combined fuzzy AHP and fuzzy TOPSIS based strategic analysis of electronic service quality in healthcare industry. Expert Syst. Appl. 2012, 39, 2341-2354. [CrossRef]

55. Zavadskas, E.K.; Susinskas, S.; Daniunas, A.; Turskis, Z.; Sivilevicius, H. Multiple criteria selection of pile-column construction technology. J. Civ. Eng. Manag. 2012, 18, 834-842. [CrossRef]

56. Buyukozkan, G.; Cifci, G. A novel hybrid MCDM approach based on fuzzy DEMATEL, fuzzy ANP and fuzzy TOPSIS to evaluate green suppliers. Expert Syst. Appl. 2012, 39, 3000-3011. [CrossRef]

57. Zavadskas, E.K.; Turskis, Z.; Volvaciovas, R.; Kildiene, S. Multi-criteria assessment model of technologies. Stud. Inform. Control 2013, 22, 249-258. [CrossRef]

58. Zavadskas, E.K.; Turskis, Z.; Tamosaitiene, J. Risk assessment of construction projects. J. Civ. Eng. Manag. 2010, 16, 33-46. [CrossRef]

59. Yazdani, M.; Payam, A.F. A comparative study on material selection of micro-electromechanical systems electrostatic actuators using Ashby, VIKOR and TOPSIS. Mater. Des. 2015, 65, 328-334. [CrossRef]

60. Greco, S.; Matarazzo, B.; Slowinski, R. Rough sets theory for multicriteria decision analysis. Eur. J. Oper. Res. 2001, 129, 1-47. [CrossRef]

61. Diakoulaki, D.; Karangelis, F. Multi-criteria decision analysis and cost-benefit analysis of alternative scenarios for the power generation sector in Greece. Renew. Sustain. Energy Rev. 2007, 11, 716-727. [CrossRef]

62. Pohekar, S.; Ramachandran, M. Application of multi-criteria decision making to sustainable energy planning-a review. Renew. Sustain. Energy Rev. 2004, 8, 365-381. [CrossRef]

63. Tian, G.; Zhang, H.; Feng, Y.; Wang, D.; Peng, Y.; Jia, H. Green decoration materials selection under interior environment characteristics: a grey-correlation based hybrid MCDM Method. Renew. Sustain. Energy. Rev. 2018, 81, 682-692. [CrossRef]

64. Hashemi, S.H.; Karimi, A.; Aghakhani, N.; Kalantar, P. A grey-besed carbon management model for green supplier selection. In 2013 IEEE International Conference on Grey systems and Intelligent Services (GSIS); IEEE: Piscatville, NJ, USA, 2014; Volume 26, pp. 402-405.

65. Sarucan, A.; Baysal, M.E.; Kahraman, C.; Engin, O. A hierarchy grey relational analysis for selecting the renewable electricity generation technologies. Lect. Notes Eng. Comput. Sci. 2011, 2, 1149-1154.

66. Ebrahimi, M.; Keshavarz, A. Prime mover selection for a residential micro CCHP by using two multi-criteria decision-making methods. Energy Build. 2012, 55, 322-331. [CrossRef]

67. Wang, J.; Zhang, C.; Jing, Y.; Zheng, G. Using the fuzzy multi-criteria model to select the optimal cool storage system for air conditioning. Energy Build. 2008, 40, 2059-2066. [CrossRef]

68. Wang, J.; Zhang, C.; Zhao, J. Review on multi-criteria decision analysis aid in sustainable energy decision-making. Renew. Sustain. Energy Rev. 2009, 13, 2263-2278. [CrossRef]

69. Lee, W.; Lin, Y. Evaluating and ranking energy performance of office buildings using grey relational analysis. Energy 2011, 36, 2551-2556. [CrossRef] 
70. Abhang, L.B.; Hameedullah, M. Determination of optimum parameters for multi-performance characteristics in turning by using grey relational analysis. Int. J. Adv. Manuf. Technol. 2012, 63, 13-24. [CrossRef]

71. Aydin, N.; Celik, E.; Gumus, A.T. A hierarchical customer satisfaction framework for evaluating rail transit systems of Istanbul. Trans. Res. Part A Policy Pract. 2015, 77, 61-81. [CrossRef]

72. Celik, E.; Aydin, N.; Gumus, A.T. A multiattribute customer satisfaction evaluation approach for rail transit network: a real case study for Istanbul, Turkey. Transp. Policy 2014, 36, 283-293. [CrossRef]

73. Feng, Y.; Zhou, M.; Tian, G.; Li, Z.; Zhang, Z.; Zhang, Q.; Tan, J. Target disassembly sequencing and scheme evaluation for $\mathrm{CNC}$ machine tools using improved multiobjective ant colony algorithm and fuzzy integral. IEEE Trans. Syst. Man Cybern. Syst. 2018. [CrossRef]

74. Tian, G.; Hao, N.; Zhou, M.; Pedrycz, W.; Zhang, C.; Ma, F.; Li, Z. Fuzzy Grey Choquet Integral for Evaluation of Multicriteria Decision Making Problems with Interactive and Qualitative Indices. IEEE Trans. Syst. Man Cybern. Syst. 2019. [CrossRef]

75. Wu, S.L.; Liu, Y.T.; Hsieh, T.Y.; Lin, Y.Y.; Chen, C.Y.; Chuang, C.H.; Lin, C.T. Fuzzy integral with particle swarm optimization for a Motor-Imagery-Based Brain-Computer interface. IEEE Trans. Fuzzy Syst. 2017, 25, 21-28. [CrossRef]

76. Zhu, L.; Zhu, C.X.; Zhang, X.Z. Method for hesitant fuzzy multi-attribute decision making based on rough sets. Control Decis. 2014, 29, 1335-1339.

77. Fu, C.; Zhao, J. Multiple attribute making method based on hesitation institution fuzzy number. Syst. Eng. 2014, 32, 131-136.

78. Lin, Y.; Lee, P.; Chang, T.; Ting, H. Multi-attribute group decision making model under the condition of uncertain information. Autom. Constr. 2008, 17, 792-797. [CrossRef]

79. Zhang, G.; He, L.H. Method based on fuzzy integral about construction and optimization of supply chain networks. Comput. Eng. Appl. 1983, 9, 173-175.

80. Yan, T.; Feng, S.; Bi, X.L. Chang, L. Grey correlation analysis and applications of drill stem failure in drilling engineering. In 2010 Seventh International Conference on Fuzzy Systems and Knowledge Discovery; IEEE: Piscatville, NJ, USA, 2010; Volume 4, pp. 1699-1702.

81. Zhu, J. Study on Measuring and Evaluating Product Innovation of Small and Medium Enterprises; Harbin University of Science and Technology: Harbin, China, 2003. (In Chinese)

82. Delgado, A.; Romero, I. Environmental conflict analysis using an integrated grey clustering and entropy-weight method: A case study of a mining project in Peru. Environ. Model. Softw. 2016, 77, 108-121. [CrossRef]

83. Delgado, M.; Herrera, F.; Herrera-Viedma, E.; Martinez, L. Combining numerical and linguistic information in group decision making. Inf. Sci. 1998, 107, 177-194. [CrossRef]

84. Herrera, F.; Martinez, L. An approach for combining linguistic and numerical information based on the 2-tuple fuzzy linguistic representation model in decision-making. Int. J. Uncertain. Fuzziness Knowl. Based Syst. 2011, 8, 539-562. [CrossRef]

85. Liu, Z.; Liu, Y.; He, B.J.; Xu, W.; Jin, G.; Zhang, X. Application and suitability analysis of the key technologies in nearly zero energy buildings in China. Renew. Sustain. Energy. Rev. 2019, 101, 329-345. [CrossRef]

86. Tian, G.; Zhou, M.; Li, P. Disassembly sequence planning considering fuzzy component quality and varying operational cost. IEEE Trans. Autom. Sci. Eng. 2018, 15, 748-760. [CrossRef]

87. Fard, A.F.; Hajiaghaei-Keshteli, M. Red Deer Algorithm (RDA); a new optimization algorithm inspired by Red Deers' mating. In International Conference on Industrial Engineering; IEEE: Piscatville, NJ, USA, 2016; Volume 12, pp. 331-342.

88. Gu, C.; Li, Z.W.; Wu, N.Q.; Khalgui, M.; Qu, T.; Al-Ahmari, A. Improved multi-step look-ahead control policies for automated manufacturing systems. IEEE Access 2018, 6, 68824-68838. [CrossRef]

89. Fathollahi-Fard, A.M.; Hajiaghaei-Keshteli, M.; Tavakkoli-Moghaddam, R. The social engineering optimizer (SEO). Eng. Appl. Artif. Intell. 2018, 72, 267-293. [CrossRef]

90. Hajiaghaei-Keshteli, M.; Fathollahi-Fard, A.M. A set of efficient heuristics and metaheuristics to solve a two-stage stochastic bi-level decision-making model for the distribution network problem. Comput. Ind. Eng. 2018, 123, 378-395. [CrossRef] 
91. Fathollahi-Fard, A.M.; Hajiaghaei-Keshteli, M.; Tavakkoli-Moghaddam, R. A bi-objective green home health care routing problem. J. Clean. Prod. 2018, 200, 423-443. [CrossRef]

92. Feng, Y.; Gao, Y.; Tian, G.; Li, Z.; Hu, H.; Zheng, H. Flexible process planning and end-of-life decision-making for product recovery optimization based on hybrid disassembly. IEEE Trans. Autom. Sci. Eng. 2019, 16, 311-326. [CrossRef]

93. Tian, G.; Ren, Y.; Feng, Y.; Zhou, M.; Zhang, H.; Tan, J. Modeling and Planning for Dual-Objective Selective Disassembly Using AND/OR Graph and Discrete Artificial Bee Colony. IEEE Trans. Ind. Inform. 2019, 15, 2456-2468. [CrossRef]

(C) 2019 by the authors. Licensee MDPI, Basel, Switzerland. This article is an open access article distributed under the terms and conditions of the Creative Commons Attribution (CC BY) license (http://creativecommons.org/licenses/by/4.0/). 